\title{
A Comparative Study on Skid Resistance of Concrete Pavements Differing in Texturing Technique
}

\author{
Pawel Gierasimiuk*(D), Marta Wasilewska and Wladyslaw Gardziejczyk (D) \\ Faculty of Civil Engineering and Environmental Science, Bialystok University of Technology, \\ 15-351 Bialystok, Poland; marta.wasilewska@pb.edu.pl (M.W.); w.gardziejczyk@pb.edu.pl (W.G.) \\ * Correspondence: p.gierasimiuk@pb.edu.pl; Tel.: +48-511-302-185
}

check for updates

Citation: Gierasimiuk, P.; Wasilewska, M.; Gardziejczyk, W. A Comparative Study on Skid Resistance of Concrete Pavements Differing in Texturing Technique. Materials 2021, 14, 178. https://doi.org/10.3390/ma14010178

Received: 9 December 2020 Accepted: 29 December 2020 Published: 1 January 2021

Publisher's Note: MDPI stays neutral with regard to jurisdictional clai$\mathrm{ms}$ in published maps and institutional affiliations.

Copyright: (C) 2021 by the authors. Licensee MDPI, Basel, Switzerland. This article is an open access article distributed under the terms and conditions of the Creative Commons Attribution (CC BY) license (https:// creativecommons.org/licenses/by/ $4.0 /)$.

\begin{abstract}
The paper presents a comparison of the skid resistance of concrete pavements textured with different techniques in the process of simulating phenomena occurring in actual road conditions. Tests were carried out on five different texturing methods for concrete pavements: burlap drag (BuD), brush drag (BrD), transverse tining (TT), longitudinal tining (LT) and exposed aggregate concrete (EAC). Changes in the skid resistance were recorded by measurements with a British pendulum tester and a circular texture meter before and during the simulation of the abrasion (1st phase of test) and polishing (2nd phase of test) of specimens using a slab polisher. The results of BPN (British pendulum number) and MPD (mean profile depth) allowed us to determine the influence of microtexture and macrotexture on skid resistance. Analysis of variance showed that the method of texturing concrete pavements has a significant influence on the mean BPN values as well as the MPD parameter at each stage of the test. In order to distinguish homogeneous groups in terms of BPN and MPD levels at the particular stages of the process, the Tukey's HSD (honest significant difference) post-hoc test was performed. It was found that EAC obtained the most favorable results of all the tested pavement types. Due to the high value of the MPD coefficient after the test and the appropriate values of the friction coefficient, it was confirmed that the EAC pavement will be a durable solution due to the guarantee of skid resistance on high-speed roads during its service life.
\end{abstract}

Keywords: skid resistance; concrete pavement; British pendulum tester; mictotexture; macrotexture

\section{Introduction}

Skid resistance is one of the features of the road surface that significantly affects the safety of users. It is defined as the characterization of the friction of a road surface when measured in accordance with a standardized method. Numerous studies have shown that the micro- and macrotexture of the pavement significantly affects the skid resistance. In the case of concrete pavements, it is related to the surface texturing technique and the characteristics of the used concrete mix. Pavements textured with burlap drag and brushes are characterized by a low resistance to the wear caused by vehicle wheels during the period of use [1,2]. Transverse and longitudinal tines of pavements provide deeper irregularities and higher durability than those obtained by jute fabric or brush texturing. The more advantageous techniques for texturing concrete pavements, both damaged and newly constructed, include the exposed aggregate concrete (EAC) method, the grinding and grooving method and the next generation concrete surface (NGCS) [3-7].

The EAC method is based on delayed cement hydration and the removal of unbound cement mortar with a mechanical brush or water under pressure. This exposes the coarse aggregate particles that protrude slightly from the top surface [8-10]. Concrete pavements with exposed aggregate are made in two layers, in the "wet on wet" system [11]. The top layer should be made of concrete mix with a maximum grain size of 8 or $11 \mathrm{~mm}[8,9]$. In the case of this type of texturing, it is important to use an aggregate with the appropriate resistance to polishing $[12,13]$. In order to verify the correctness of the macrotexture, the criteria for the 
number of exposed coarse aggregate grains on an area of $25 \mathrm{~cm}^{2}$ were established; the works were conducted mainly in Germany and Austria $[8,9,12,14,15]$. However, this method of evaluation is time-consuming. The measurement of the parameters describing the macrotexture is easier to perform in order to control the quality of the pavement surface.

The texturing technique using diamond blades (diamond grinding), in addition to leveling longitudinal irregularities, improves the micro- and macrotexture by producing small irregularities and grooves. The next generation concrete surface (NGCS) is the best known method which uses diamond blades [16-20]. This method allows one to obtain a negative texture, and thanks to the optimal placement of the blades, it provides a durable macrotexture and a high level of microtexture [21]. The macrotexture and microtexture of the surface determine the skid resistance of concrete pavements. Maintaining the required level of skid resistance allows one to reduce the accident rate on wet surfaces even up to $70 \%[22,23]$. This is confirmed by studies presenting analyses describing the relationship between the number of road incidents and the decrease in the friction coefficient in adverse weather conditions [22,24-27].

Macrotexture depends on the shape, size and gradation graining of the aggregate, and has an effect on skid resistance, especially at high vehicle speed. The MPD (mean profile depth) value is the most frequently used parameter describing the surface macrotexture. The use of laser profilographs, which enable measurements in real traffic conditions, allows for a quick assessment of the macrotexture of the upper layers during the pavement's use. A high macrotexture allows water to drain away through a system of external voids and reduces the aquaplaning phenomenon. On the other hand, microtexture is responsible for breaking the water film at the contact zone between the tire and the road surface, where a dry contact zone is created [28-30]. It is important at all speeds. Microtexture depends on the polishing resistance of the coarse aggregate and the content of fine aggregate in the asphalt mixture [31]. The parameter indirectly describing the microtexture is the value of the friction coefficient determined with the use of dynamic devices from the locked-wheel tester group, or stationary devices such as the British pendulum tester or DFT $[32,33]$.

Studies on the skid resistance of concrete pavements were mainly based on the results obtained on in situ road sections [34-39]. The variety of dynamic devices for measuring the friction coefficient used in different countries is an issue. Works on harmonizing these measurement methods in Europe are well advanced now. The effects of the last Common Scale elaborations under the ROSANNE project were verified during two European Pavement Friction Workshops (EPFW) held in Nantes, France, in 2017 and 2019. Additionally, an effort has been made to carry out studies to develop the harmonization of dynamic devices based on the IFI (international friction index) using the reference CTM and DFT stationary devices [40]. The lack of a common scale for all the dynamic devices that are used in the world significantly hinders the exchange of information related to the skid resistance of road surfaces.

It should be noted that not all the devices used in the world to assess skid resistance were considered in the ROSANNE and EPFW projects. Therefore, in order to compare different types of pavements, devices for the laboratory assessment of skid resistance are very helpful, because they guarantee the same conditions representing the factors influencing the changes in macrotexture and microtexture in real road conditions. Thanks to them, it is possible to create a ranking of the materials intended for the upper layers of pavements in terms of their skid resistance. Many research approaches have been created that enable the simulation of the phenomena responsible for these changes. A well-known device is the German FAP machine (also called Wehner/Schuzle machine). However, works on developing a relationship between the results obtained in the laboratory and for in-service pavements are still ongoing $[13,36,37,41,42]$. Numerous polishing stations have also been created around the world, where tires roll on samples prepared from materials intended for the wearing course. The number of wheel passes, the load applied, or the addition of water or abrasive is optional depending on the test procedure developed. Skid resistance is very often assessed by measurements using stationary devices, such as the British pendulum 
tester or DFT. Due to the fact that the results of the measurements with these devices are sensitive to microtexture, the parameter describing the macrotexture is measured in order to comprehensively assess the skid resistance of the tested surfaces [43-46]. The assessment of the skid resistance, detailing the changes related to the microtexture and the macrotexture of the tested surfaces, is very valuable information at the planning and design stage of the upper layers of road pavements.

The aim of this study is to compare the skid resistances of cement concrete pavements textured with various techniques in a process simulating the phenomena occurring in the real conditions on roads.

\section{Materials and Methods}

\subsection{Preparation of Concrete Pavement Specimens}

The tests were performed on concrete slabs textured with the following methods:

- $\quad$ burlap drag (longitudinally to the road axis) (BuD);

- $\quad$ brush drag (in the direction perpendicular to the road axis) (BrD);

- $\quad$ transverse tined (in the direction perpendicular to the road axis) (TT);

- longitudinal tined (in the direction parallel to the road axis) (LT);

- $\quad$ exposed aggregate concrete pavement (EAC).

In the case of the EAC, two types of aggregate, differing in maximum grain size, were used: $0 / 8 \mathrm{~mm}(\mathrm{EAC} 8)$ and $0 / 11 \mathrm{~mm}$ (EAC11). The remaining concrete pavement samples, textured with the BuD, BrD, TT and LT methods, were made with aggregate $0 / 16 \mathrm{~mm}$. A trachybasalt was used as coarse aggregate.

Figure 1 shows the particle size distribution curves of the aggregate used to make concrete slabs for particular texturing techniques.

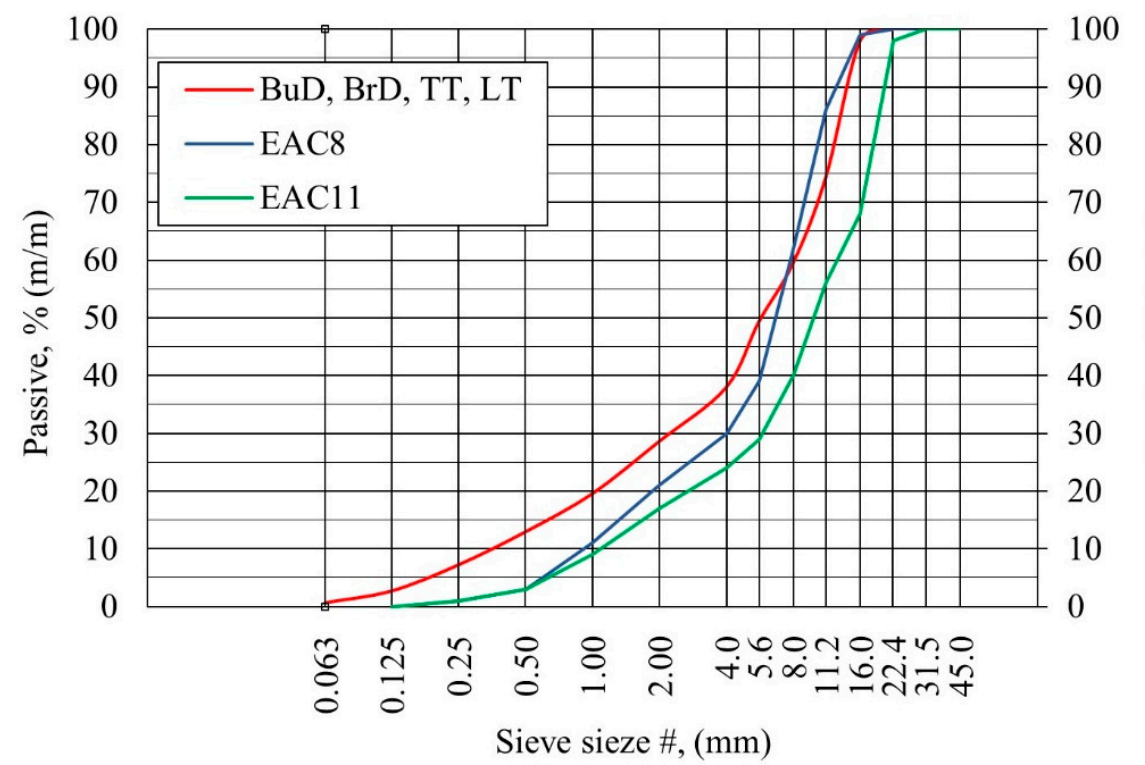

Figure 1. Particle size distribution curves of concrete mixtures.

Tables 1 and 2 provide the characteristics of the designed concrete mixtures, and the properties of the concrete mixtures and hardened concrete. 
Table 1. Characteristics of the designed concrete mixtures.

\begin{tabular}{|c|c|c|c|}
\hline Property & BrD; BuD; TT; LT & EAC8 & EAC11 \\
\hline Strength class & C $35 / 45$ & $\mathrm{C} 35 / 45$ & C $35 / 45$ \\
\hline $\begin{array}{l}\text { Consistency class acc. to } \\
\text { PN-EN 12350-3 [47] }\end{array}$ & $\mathrm{V} 2$ & $\mathrm{~V} 2$ & $\mathrm{~V} 2$ \\
\hline Exposure class & $\mathrm{XF} 4$ & XF4 & XF4 \\
\hline $\mathrm{D}_{\max }(\mathrm{mm})$ & 16 & 8 & 11 \\
\hline Cement type and class & CEM I $42.5 \mathrm{R}$ & CEM I $42.5 \mathrm{R}$ & CEM I $42.5 \mathrm{R}$ \\
\hline Cement $\left(\mathrm{kg} / \mathrm{m}^{3}\right)$ & 400.0 & 440.0 & 440.0 \\
\hline $\mathrm{w} / \mathrm{c}$ & 0.36 & 0.38 & 0.38 \\
\hline Fine aggregate & $0 / 2$ & $0 / 2$ & $0 / 2$ \\
\hline Coarse aggregate & $\begin{array}{c}2 / 5,4 / 8,8 / 11 \\
11 / 16\end{array}$ & $2 / 5,4 / 8$ & $2 / 5,4 / 8,8 / 11$ \\
\hline Admixture 1 & Air-entraining & Air-entraining & Air-entraining \\
\hline Admixture 2 & $\begin{array}{l}\text { Water reducing } \\
\text { admix. based on } \\
\text { polycarboxylates } \\
\text { and phosphonates }\end{array}$ & $\begin{array}{l}\text { Water reducing } \\
\text { admix. based on } \\
\text { polycarboxylates } \\
\text { and phosphonates }\end{array}$ & $\begin{array}{l}\text { Water reducing } \\
\text { admix. based on } \\
\text { polycarboxylates } \\
\text { and phosphonates }\end{array}$ \\
\hline
\end{tabular}

Table 2. Properties of concrete mixtures and hardened concrete with trachybasalt coarse aggregate.

\begin{tabular}{cccc}
\hline Property & $\begin{array}{c}\text { BrD; BuD; } \\
\text { TT; LT }\end{array}$ & EAC8 & EAC11 \\
\hline Air content acc. to PN-EN 12350-7 [48] $(\%)$ & 5.0 & 5.0 & 5.1 \\
Density acc. to PN-EN 12350-6 [49] $\left(\mathrm{kg} / \mathrm{m}^{3}\right)$ & 2433 & 2453 & 2410 \\
Density acc. to PN-EN 12390-7 [50] $\left(\mathrm{kg} / \mathrm{m}^{3}\right)$ & 2380 & 2413 & 2376 \\
Compressive strength acc. to PN-EN 12390-3 [51](MPa) & 59.0 & 60.5 & 50.5 \\
Flexural strength acc. to PN-EN 12390-5 [52] (MPa) & 6.9 & 8.0 & 7.4 \\
Freezing/thawing in the presence of deicing agents, & FT2 & FT2 & FT2 \\
freeze resistance category acc. to PN-EN 13877-2 [53] & & & \\
\hline
\end{tabular}

The dimensions of the test slabs were $35 \mathrm{~cm} \times 35 \mathrm{~cm} \times 5 \mathrm{~cm}$. They were compacted on a vibrating table. Six slabs were made for each texturing technique, of which four were randomly selected for testing. Each of the slabs was prepared in a separate technological process.

Transverse and longitudinal tining, and burlap and brush drag were performed on the fresh concrete mixtures, immediately after compacting each slab. The EAC method was carried out in two stages-immediately after compaction, the top surface of the slab was sprayed with a hydration-retarding agent based on paraffin wax and polyalcohol, and after about $24 \mathrm{~h}$ the non-hydrated layer of cement mortar was removed with a steel brush, which left the exposed grains of coarse aggregate. Figure 2 shows images of the top surfaces of the tested concrete slabs.

\subsection{Test Methods}

Concrete slabs were subjected to abrasion and polishing in laboratory conditions. This was a simulation of the phenomena occurring in real conditions on the surfaces of road pavements under the influence of pollutants, water and car traffic. For this purpose, the slab polisher was used (Figure 3). The slab polisher is a proprietary device built at the Bialystok University of Technology (Bialystok, Poland). The machine consists of three smooth rubber wheels mounted on a rotating disk and rolling on the surfaces of the specimens. The polishing wheels move at the velocity of $50 \pm 2$ rotations per minute. The test lasted $6 \mathrm{~h}$ and consisted of two three-hour phases. In the first phase water and coarse emery $(300 / 600 \mu \mathrm{m})$ were fed continuously onto the surfaces and in the second phase water and emery flour $(<53 \mu \mathrm{m})$ were fed. A more detailed description of the slab polisher and examples of the results of the research can be found in the literature $[9,54]$. 


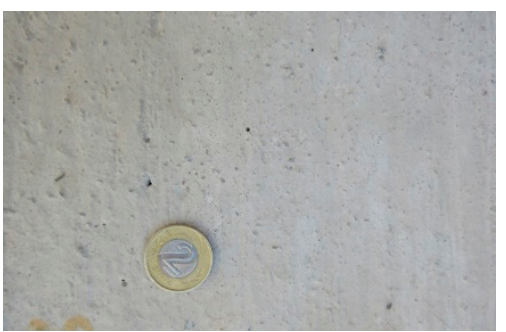

(a)

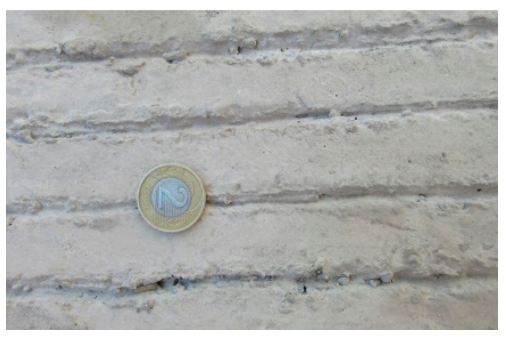

(d)

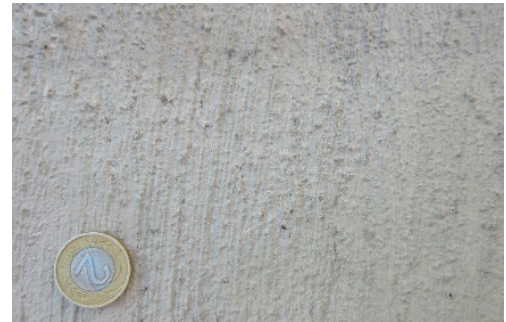

(b)

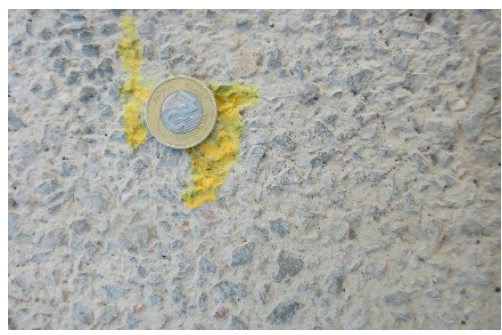

(e)

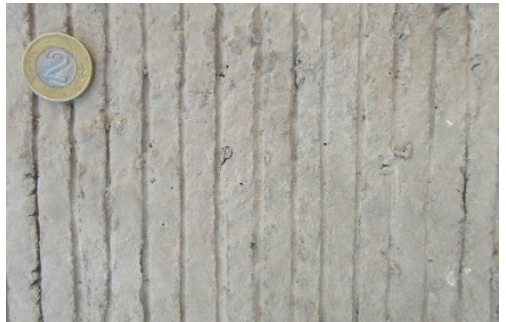

(c)

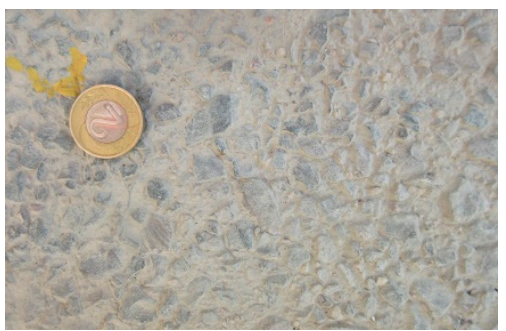

(f)

Figure 2. Slab textures: (a) BuD, (b) BrD, (c) TT, (d) LT, (e) EAC8, (f) EAC11 (diameter of the presented coin is $21.5 \mathrm{~mm}$ ).

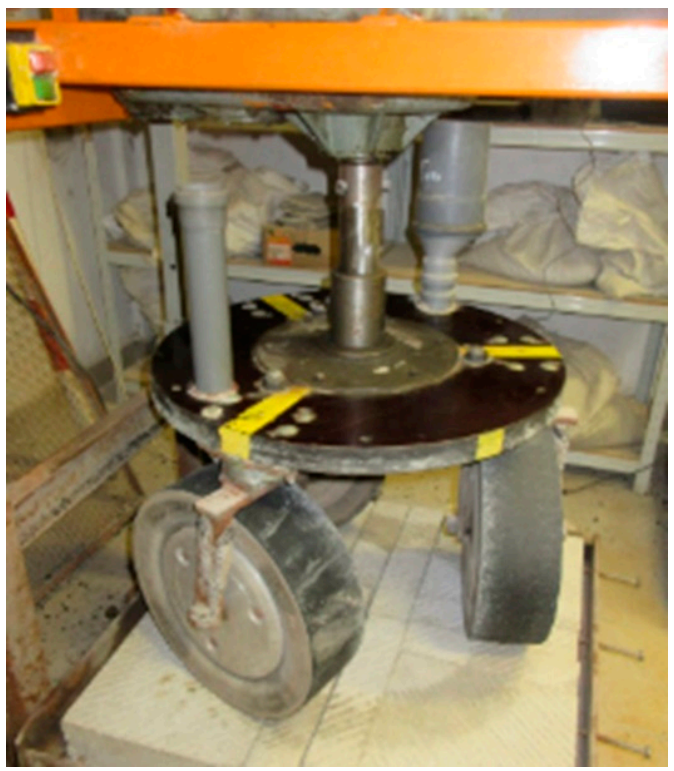

Figure 3. Slab polisher.

Skid resistance was determined on the basis of BPN measurements in accordance with ASTM E303-93 [55] (Figure 4a). The shift length of the rubber slider was $126 \pm 2 \mathrm{~mm}$ (Figure $4 \mathrm{~b}$ ). The measurements were made in the traces left by the polishing wheels on the surfaces of the specimens before and after the individual phases. Three replicate passes were performed on each tested specimen. Before each measurement using the British pendulum tester, each specimen was thoroughly washed-corundum and fine pollutions were removed. This procedure is also performed in other devices of this type, e.g., in the FAP device (known as Wehner/Schulze, Wennigsen, Germany). 


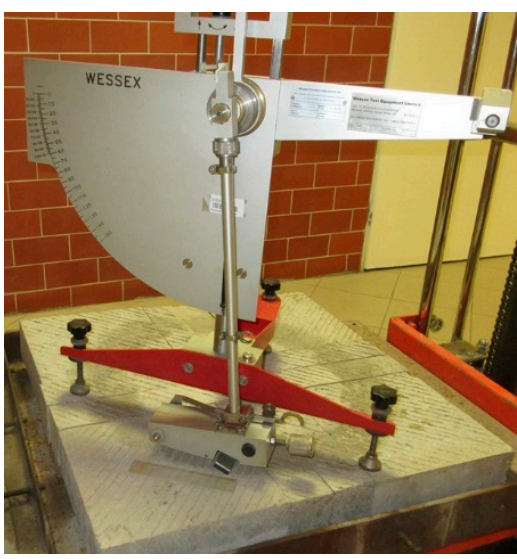

(a)

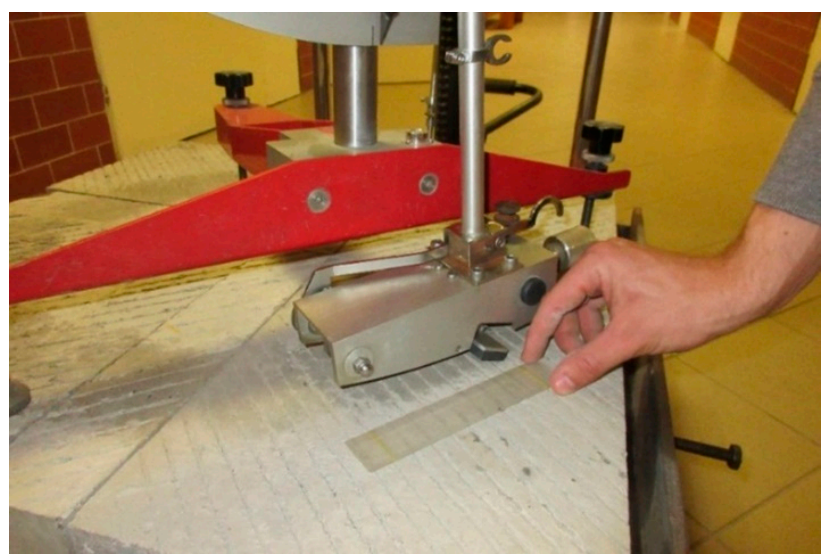

(b)

Figure 4. (a) Measurement with British pendulum tester. (b) Setting the shift length of the rubber slider.

The assessment of the macrotexture of the concrete slabs was performed by measuring the MPD parameter with the circular texture meter in accordance with ASTM E2157-15 (2019) [56] (Figure 5a). Due to the fact that the CTM scans the profile along a perimeter divided into 8 segments, in the cases of slabs with directional texturing (Bud, BrD, TT, LT), the MPD values were read only from the appropriate parts of the tested surfaces (Figure 5b).

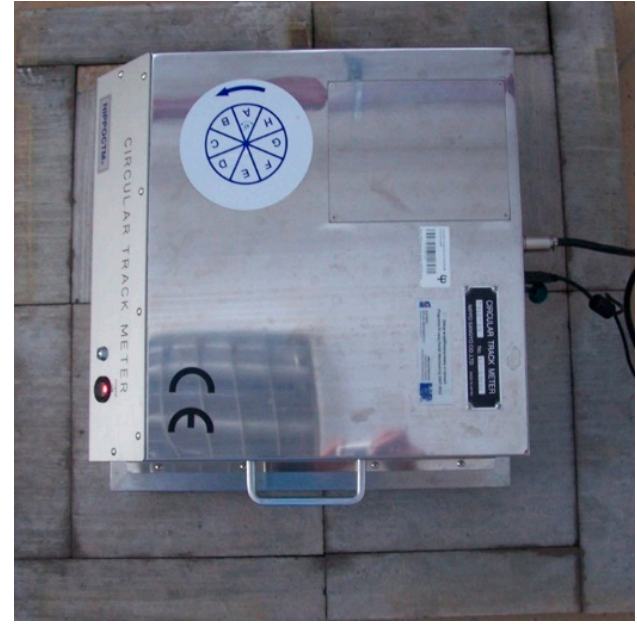

(a)

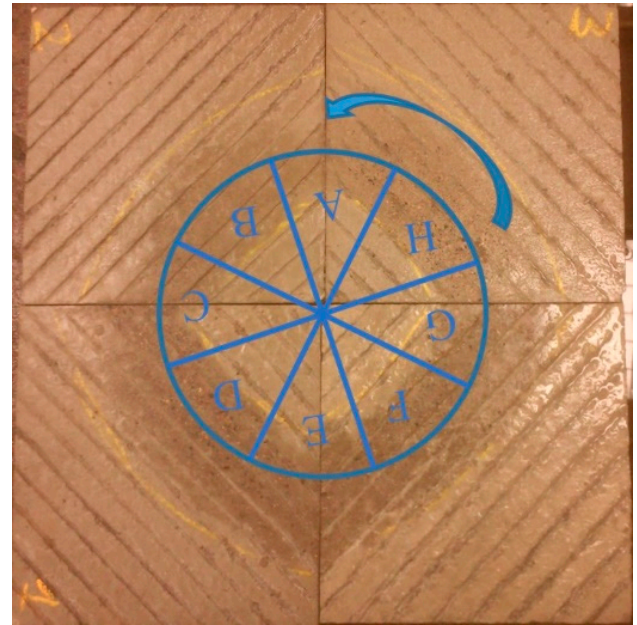

(b)

Figure 5. (a) Measurement of macrotexture with CTM, (b) the arrangement of the segments during the measurement on an example slab LT.

On each of the test slabs, BPN measurements were taken at three points prior to the polishing and during the process:

- $\quad$ in phase I after 5, 10, 15, 30, 60, 90, 120, 150 and $180 \mathrm{~min}$;

- $\quad$ in phase II after 185, 190, 195, 210, 240, 270, 300, 330 and $360 \mathrm{~min}$.

Measurements of the MPD parameter were takenon each of the concrete slabs before the process was started, after phase I and after phase II, over three repetitions. 


\section{Results and Discussion}

3.1. Changes in Skid Resistance during the Polishing Process

3.1.1. Changes in BPN Value

Table 3 shows the descriptive statistics of BPN values at different stages of polishing (mean value $(\overline{\mathrm{BPN}})$, standard deviation (STD), coefficient of variation $(\mathrm{V})$, minimum and maximum $\left.\left(\mathrm{BPN}_{\min }, \mathrm{BPN}_{\max }\right)\right)$.

Table 3. Descriptive statistics of BPN values of concrete pavements.

\begin{tabular}{|c|c|c|c|c|c|c|}
\hline $\begin{array}{l}\text { Texturing } \\
\text { Method }\end{array}$ & Stage of Test & $\overline{\mathrm{BPN}},(-)$ & STD, (-) & $\mathrm{V},(\%)$ & $\mathrm{BPN}_{\min },(-)$ & $\mathrm{BPN}_{\max },(-)$ \\
\hline \multirow{3}{*}{$\mathrm{BuD}$} & Before phase I & 55 & 7.2 & $13 \%$ & 44 & 67 \\
\hline & After phase I & 65 & 1.4 & $2 \%$ & 61 & 66 \\
\hline & After phase II & 48 & 1.3 & $3 \%$ & 46 & 51 \\
\hline \multirow{3}{*}{$\mathrm{BrD}$} & Before phase I & 77 & 5.1 & $7 \%$ & 70 & 86 \\
\hline & After phase I & 70 & 1.7 & $3 \%$ & 66 & 73 \\
\hline & After phase II & 59 & 1.7 & $3 \%$ & 55 & 61 \\
\hline \multirow{3}{*}{$\mathrm{TT}$} & Before phase I & 79 & 6.6 & $8 \%$ & 70 & 90 \\
\hline & After phase I & 69 & 3.9 & $6 \%$ & 65 & 81 \\
\hline & After phase II & 60 & 2.5 & $4 \%$ & 56 & 65 \\
\hline \multirow{3}{*}{ LT } & Before phase I & 66 & 4.0 & $6 \%$ & 60 & 76 \\
\hline & After phase I & 63 & 3.4 & $5 \%$ & 55 & 68 \\
\hline & After phase II & 51 & 1.6 & $3 \%$ & 48 & 54 \\
\hline \multirow{3}{*}{ EAC8 } & Before phase I & 76 & 3.6 & $5 \%$ & 69 & 81 \\
\hline & After phase I & 59 & 0.9 & $1 \%$ & 58 & 61 \\
\hline & After phase II & 52 & 1.3 & $2 \%$ & 50 & 55 \\
\hline \multirow{3}{*}{ EAC11 } & Before phase I & 73 & 2.6 & $4 \%$ & 70 & 80 \\
\hline & After phase I & 61 & 1.2 & $2 \%$ & 59 & 64 \\
\hline & After phase II & 56 & 1.5 & $3 \%$ & 53 & 58 \\
\hline
\end{tabular}

Specimens with the transverse texturing direction, $\mathrm{BrD}$ and $\mathrm{TT}$, were characterized by high BPN values compared to other tested technologies (Figure $6 b, c$ ). This is due to the fact that the direction of the pendulum arm was perpendicular to the groove system. On the other hand, in the case of the LT surface (Figure 6d), the direction of the pendulum arm during the measurement was parallel to the groove system. The circumstances of the measurement in the laboratory were also due to the texture pattern of the actual road conditions. Consequently, the $\mathrm{BrD}$ and TT texturing techniques allow one to achieve higher $\mathrm{BPN}$ values compared to LT. The BuD surface reached low BPN values at the end of the test, comparable to the LT values.

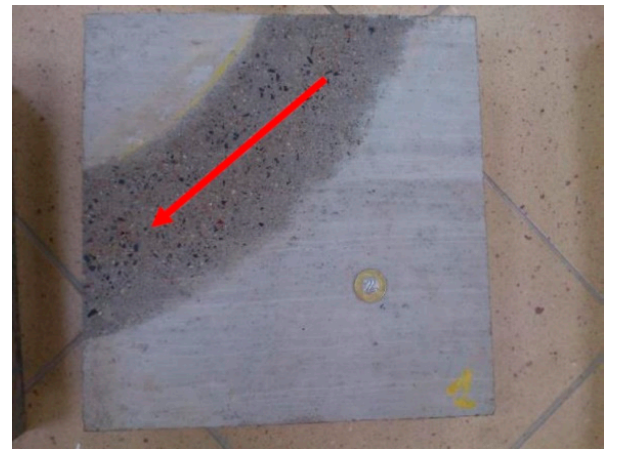

(a)

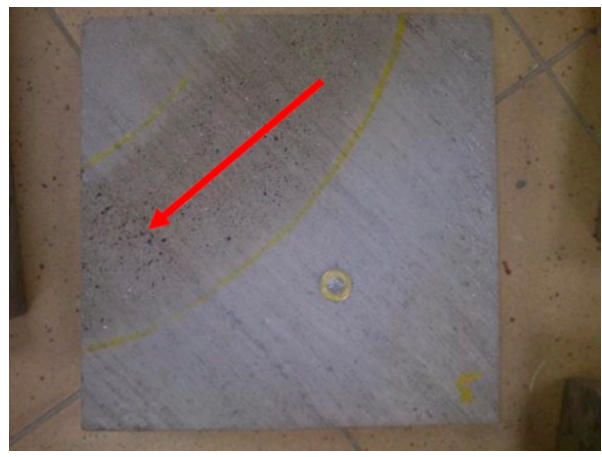

(b)

Figure 6. Cont. 


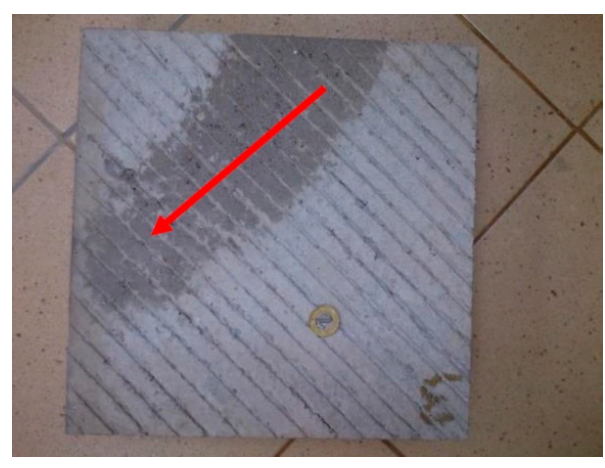

(c)

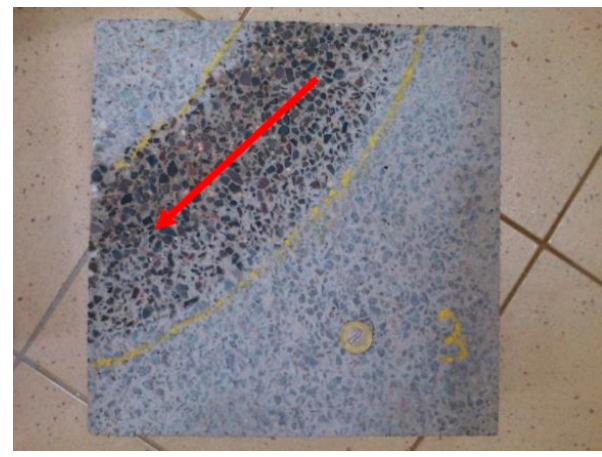

(e)

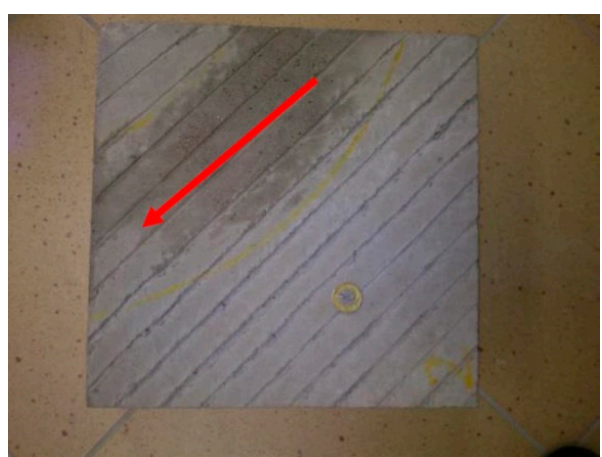

(d)

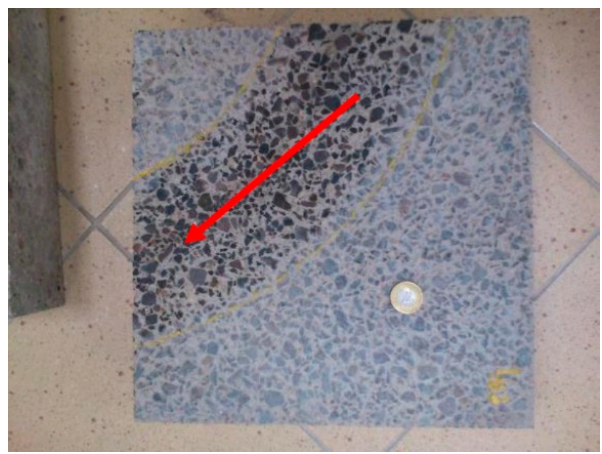

(f)

Figure 6. Textures of concrete pavements with the marked measurement direction of the British pendulum tester: (a) BuD, (b) BrD, (c) TT, (d) LT, (e) EAC8, (f) EAC11 (diameter of the presented coin is $21.5 \mathrm{~mm}$ ).

EAC pavements do not have a directed texture (Figure 6e,f). Higher BPN values in the polishing process were achieved by the EAC11 surface, which reached higher values at each stage of polishing.

After the first phase of the process, in the cases of pavements with the texture types $\mathrm{BuD}, \mathrm{BrD}$, TT and $\mathrm{LT}$, a decrease of $5-13 \%$ in the BPN values was recorded compared to the initial values. In the cases of $\mathrm{BrD}$ and TT slabs, the BPN values changed at a similar level (Figure 7). This was influenced by the lateral orientation of the grooves (TT) and the unevenness resulting from the lateral brushing $(\mathrm{BrD})$ in relation to the direction of operation of the polishing wheels in the slab polisher.

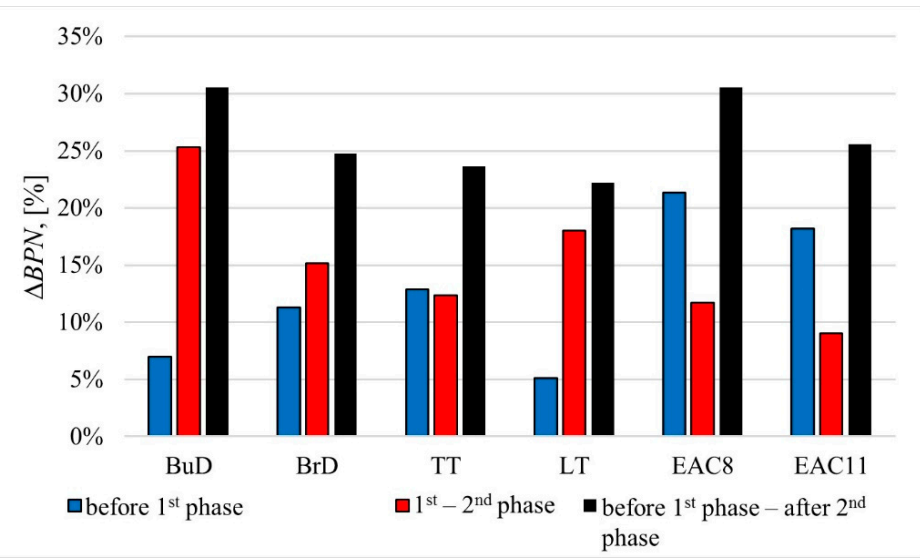

Figure 7. The percentage decrease in BPN between the individual phases of the polishing process.

The BPN values for the EAC samples decreased by $21 \%$ and $18 \%$ after the first phase, and by $12 \%$ and $9 \%$ in the second phase (EAC 8 and EAC11, respectively). In the case of 
the rest of the tested specimens, decreases in the BPN values ranging from 12 to $25 \%$ were recorded in phase II.

Based on the values recorded during the particular phases, interesting tendencies were noticed when subjecting the samples to factors related to the simulation of phenomena occurring in the real conditions. Changes in the BPN values, along with standard deviations recorded in the particular test phases, are shown in Figure 8.

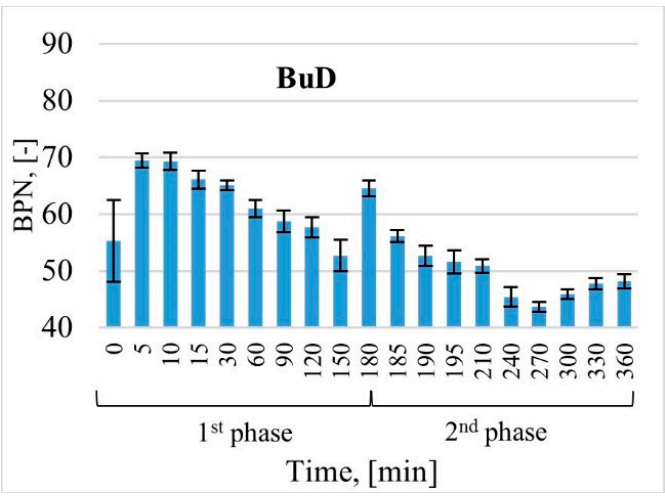

(a)

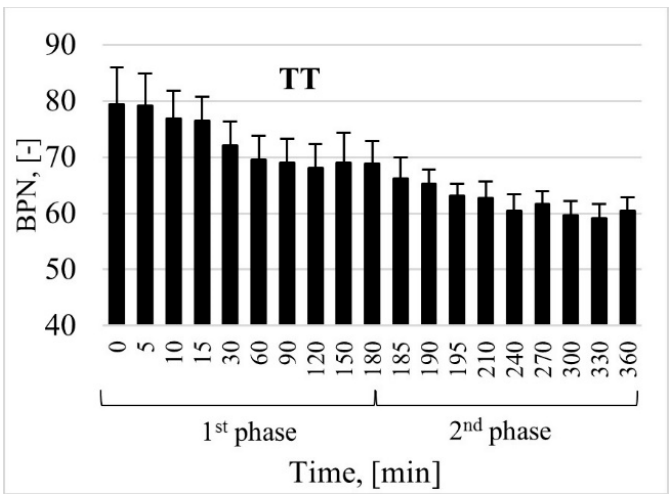

(c)

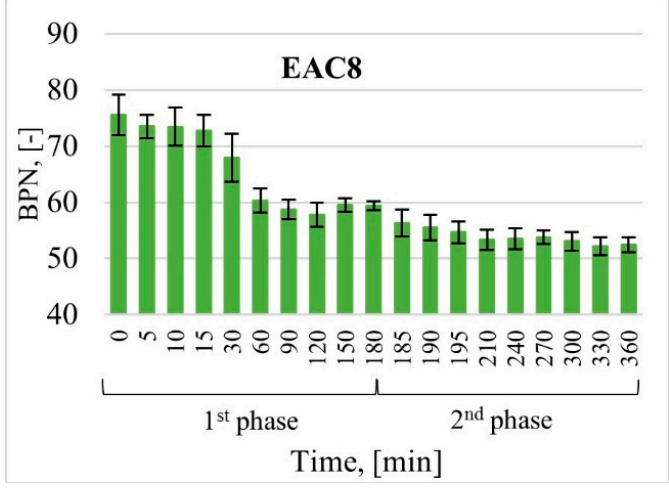

(e)

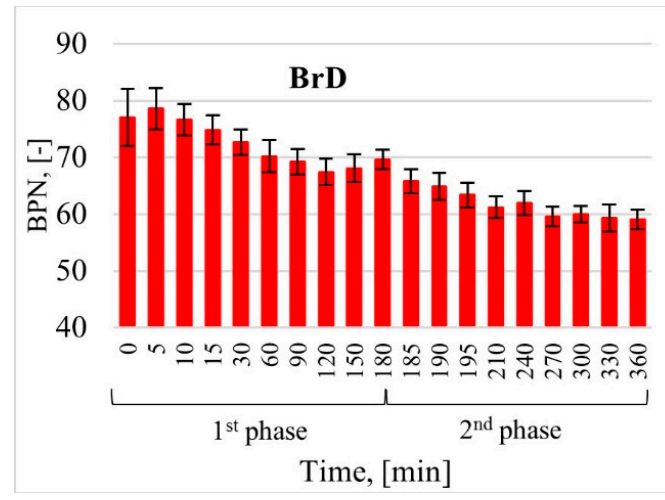

(b)

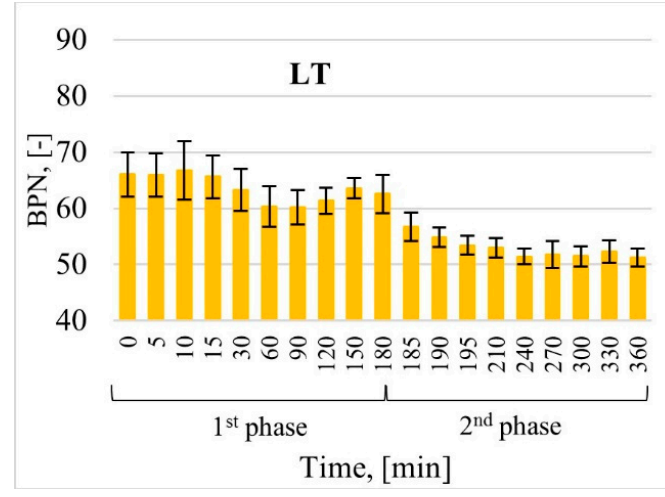

(d)

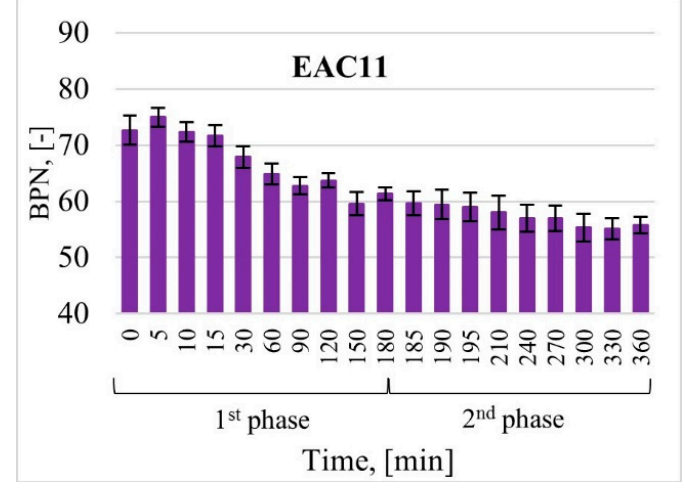

(f)

Figure 8. Changes in the mean BPN values of concrete pavements textured by (a) burlap drag, (b) brush drag, (c) transverse tining, (d) longitudinal tining, (e) EAC8, (f) EAC11.

In real traffic conditions, surfaces are exposed to polishing, abrasion and weathering as a result of car traffic, water, pollution and weather conditions [57]. Due to the fact that these phenomena occur simultaneously but with varying intensity depending on climatic conditions, it is difficult to reproduce them in laboratory conditions. In the case of the slab polisher, it was determined that the addition of coarse emery $(300 / 600 \mu \mathrm{m})$ would 
contribute to conditions favorable to abrasion, while emery flour $(<53 \mu \mathrm{m})$ to polishing. Such test conditions are those under which the polishing resistance of coarse aggregates is assessed according to EN 1097-8. The variation in BPN values varied depending on the texturing method. For BrD, TT, LT and EAC, a slight decrease in BPN was observed during the first $30 \mathrm{~min}$. After $60 \mathrm{~min}$, this value stabilized at a certain level and only insignificant differences were recorded until the end of phase I. This is related to changes in the microtextures of surfaces. Coarse emery, which is spread on the surface under the movement of wheels, rubs the cement mortar, removes it from the surface and creates micro-grooves. As a consequence, the minerals changed their original appearance. The tests conducted on coarse aggregates have shown that in this phase, polished surfaces with a characteristic gloss are also observed; however, the surfaces of numerous abrasion marks predominate [58]. Slight differences in BPN values showing both decreasing and increasing trends appeared in phase I after $60 \mathrm{~min}$, which were related to the effects of the polishing and abrasion of the surface. While the trends of these changes were visible on the $\mathrm{BrD}, \mathrm{TT}$, LT and EAC surfaces, the decreases and increases in BPN were not large. In the cases of the BuD surfaces, the recorded decreases and increases in BNP were significant. After 180 min, the BPN value was comparable to the 30 min test result.

On all tested surfaces, due to the presence of emery flour and water, lower final values were obtained compared to the values after the end of phase I. This decrease is related to the smoothing of the surface due to its polishing.

In order to recognize the mechanisms responsible for BPN changes during polishing, images of the surfaces before and after the test were analyzed under an optical-digital microscope. In the case of jute dragging-textured slabs, the polishing process removed the top layer of cement mortar. At this stage, the cement mortar with exposed fine aggregate is mainly responsible for the skid resistance (Figure 9a). In the case of tined and brushed slabs, the grooves and unevenness were damaged during polishing, which resulted in a decrease in the BPN values (Figure 9b-d). The values of the friction coefficient were mainly influenced by the unevenness resulting from the texturing method and the presence of fine aggregate exposed in the cement mortar. Fine aggregate grains were also visible on the surfaces.
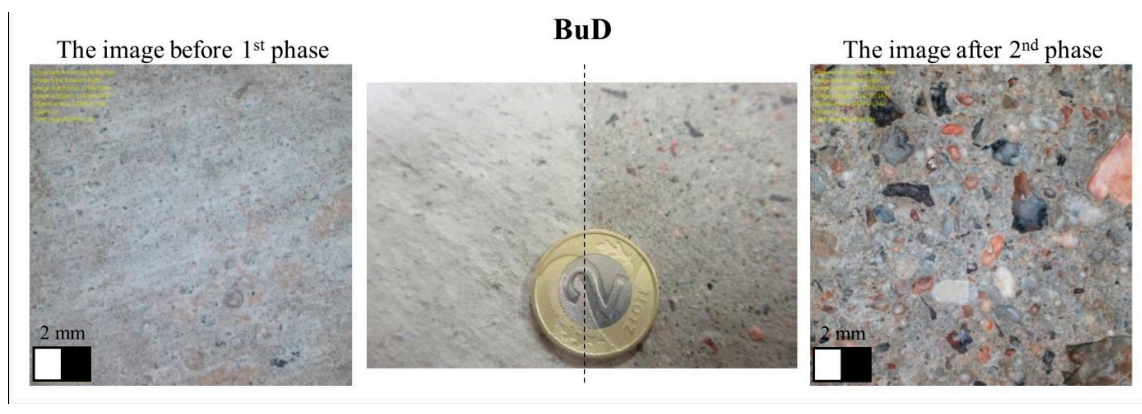

(a)
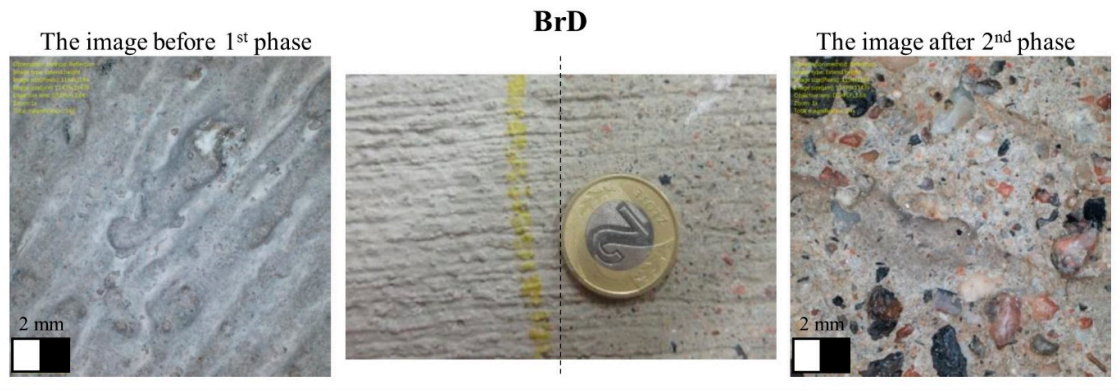

(b)

Figure 9. Cont. 

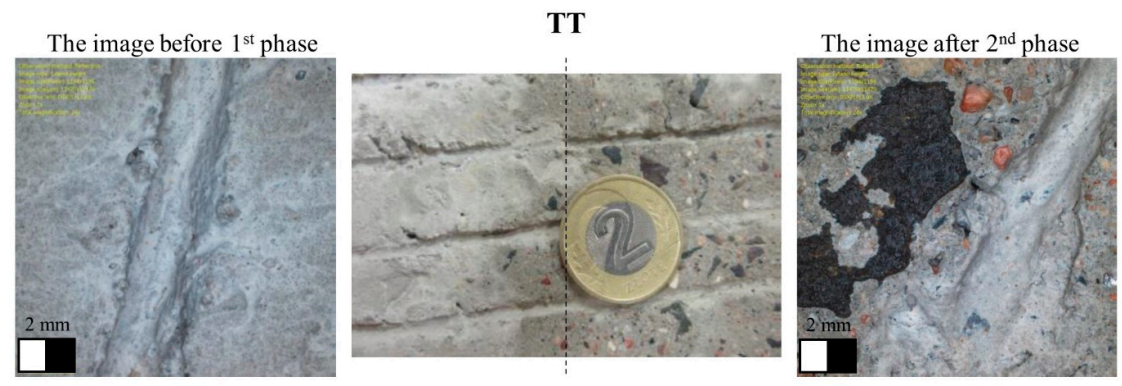

(c)

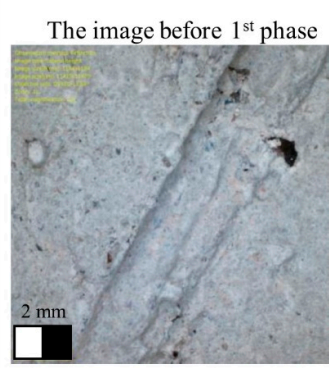

LT

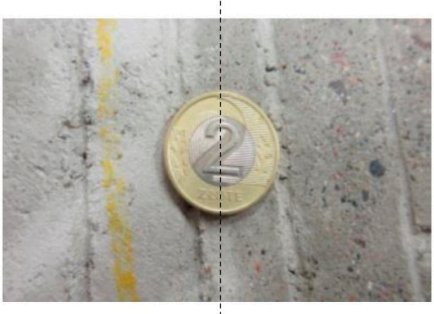

The image after $2^{\text {nd }}$ phase

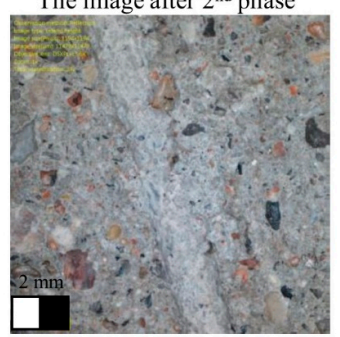

(d)
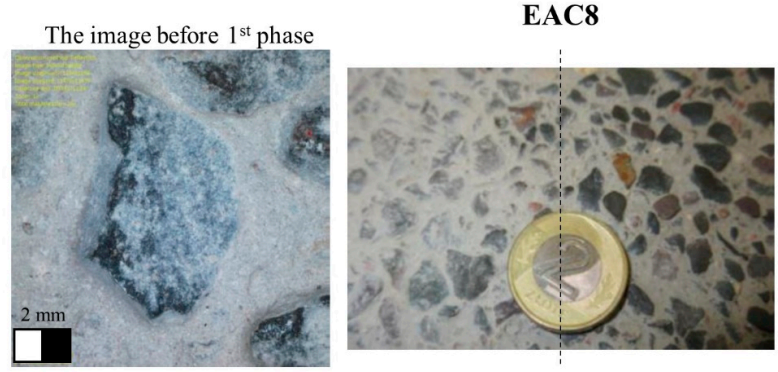

The image after $2^{\text {nd }}$ phase

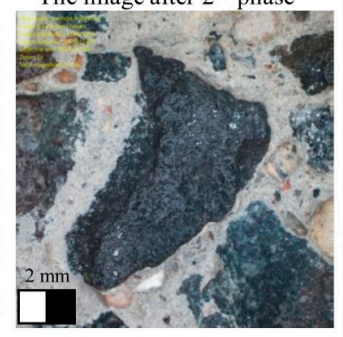

(e)
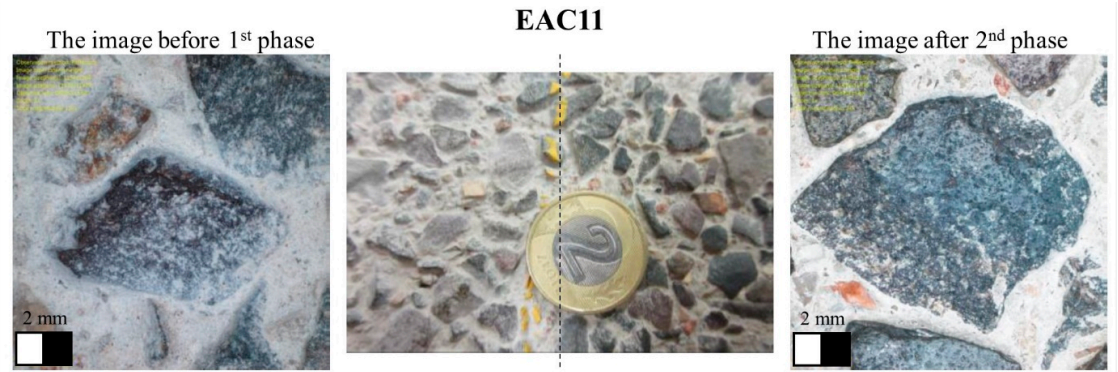

(f)

Figure 9. The surfaces of concrete specimens (diameter of the presented coin is $21.5 \mathrm{~mm}$ ) and images from an optical-digital microscope: (a) BuD, (b) BrD, (c) TT, (d) LT, (e) EAC8, (f) EAC11.

Coarse aggregate plays a more important role in EAC surfaces. Cement mortar was removed from the surfaces of the aggregate grains as a result of polishing (Figure 9e,f), and the exposed coarse aggregate grains could be treated with polishing agents. It should be noted that the contact surface on the aggregate often amounted to less than $50 \%$ of the surface of the protruding grain [59]. 


\subsubsection{Changes in Surface Macrotexture}

Table 4 presents descriptive statistics calculated on the basis of the MPD measurement results - mean value ( $\overline{\mathrm{MPD}}$ ), standard deviation (STD), coefficient of variation (V), and minimum and maximum $\left(\mathrm{MPD}_{\min }\right.$ and $\left.\mathrm{MPD} \mathrm{D}_{\max }\right)$ values. Figure 10 shows the profiles of surface roughness, before polishing and after phase II.

Table 4. Descriptive statistics of MPD.

\begin{tabular}{ccccccc}
\hline $\begin{array}{c}\text { Texturing } \\
\text { Method }\end{array}$ & Stage of Test & MPD, (mm) & $\begin{array}{c}\text { STD, } \\
\text { (mm) }\end{array}$ & V, (\%) & $\begin{array}{c}\text { MPD }_{\text {Min }} \\
\text { (mm) }\end{array}$ & $\begin{array}{c}\text { MPD }_{\text {Max }} \\
\text { (mm) }\end{array}$ \\
\hline \multirow{3}{*}{ BuD } & Before phase I & 0.27 & 0.1 & $36 \%$ & 0.18 & 0.55 \\
& After phase I & 0.23 & 0.06 & $26 \%$ & 0.15 & 0.40 \\
& After phase II & 0.26 & 0.09 & $33 \%$ & 0.13 & 0.40 \\
\multirow{2}{*}{ BrD } & Before phase I & 0.75 & 0.17 & $23 \%$ & 0.51 & 1.06 \\
& After phase I & 0.25 & 0.06 & $23 \%$ & 0.17 & 0.40 \\
& After phase II & 0.25 & 0.08 & $32 \%$ & 0.11 & 0.40 \\
\multirow{2}{*}{ TT } & Before phase I & 0.80 & 0.13 & $17 \%$ & 0.56 & 0.97 \\
& After phase I & 0.47 & 0.11 & $23 \%$ & 0.34 & 0.78 \\
& After phase II & 0.47 & 0.12 & $26 \%$ & 0.31 & 0.78 \\
\multirow{2}{*}{ LT } & Before phase I & 0.49 & 0.14 & $29 \%$ & 0.32 & 0.74 \\
& After phase I & 0.32 & 0.11 & $36 \%$ & 0.17 & 0.45 \\
& After phase II & 0.30 & 0.11 & $37 \%$ & 0.15 & 0.45 \\
EAC8 & Before phase I & 1.15 & 0.26 & $22 \%$ & 0.85 & 1.57 \\
& After phase I & 0.90 & 0.17 & $19 \%$ & 0.62 & 1.11 \\
& After phase II & 0.81 & 0.14 & $17 \%$ & 0.61 & 1.11 \\
EAC11 & Before phase I & 1.11 & 0.13 & $11 \%$ & 0.92 & 1.35 \\
& After phase I & 0.91 & 0.12 & $13 \%$ & 0.73 & 1.16 \\
& After phase II & 0.84 & 0.13 & $16 \%$ & 0.67 & 1.16 \\
\hline
\end{tabular}

a)

before $1^{\text {st }}$ phase

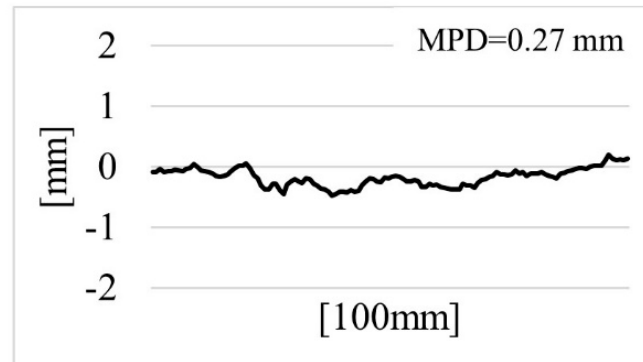

b)

before $1^{\text {st }}$ phase

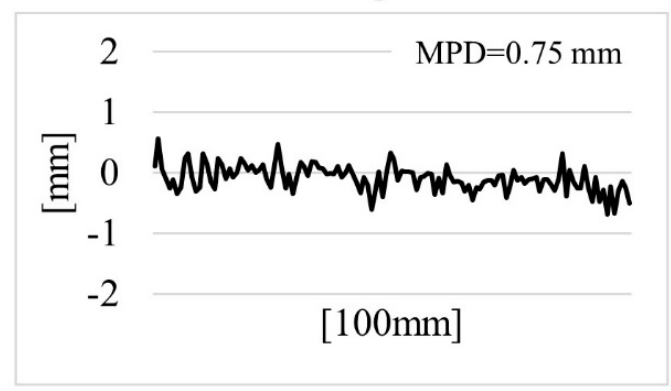

BuD

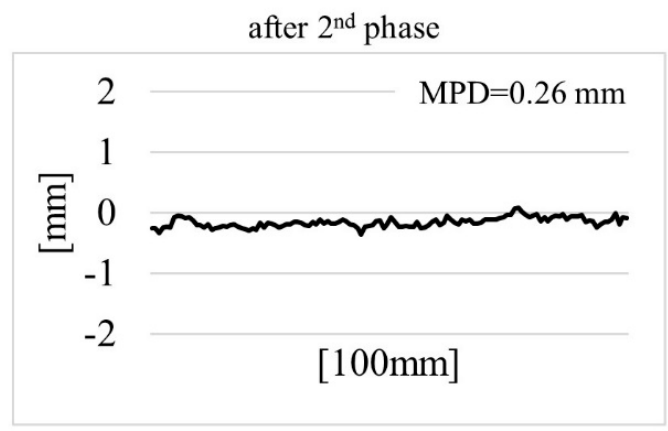

BrD

after $2^{\text {nd }}$ phase

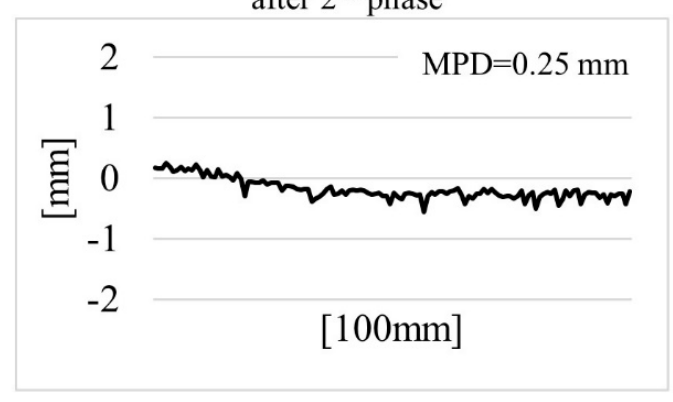

Figure 10. Cont. 
c)

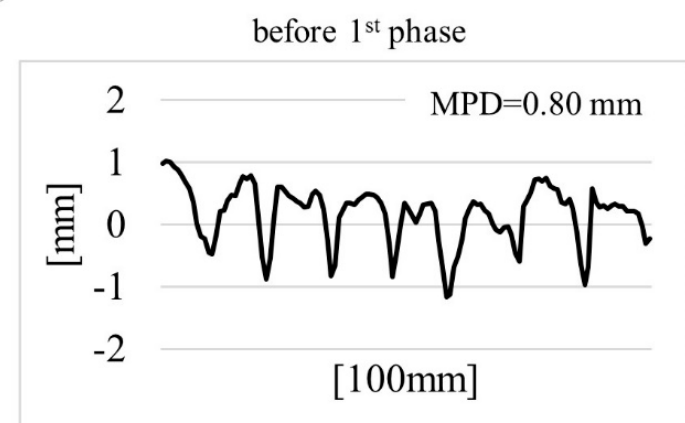

d)

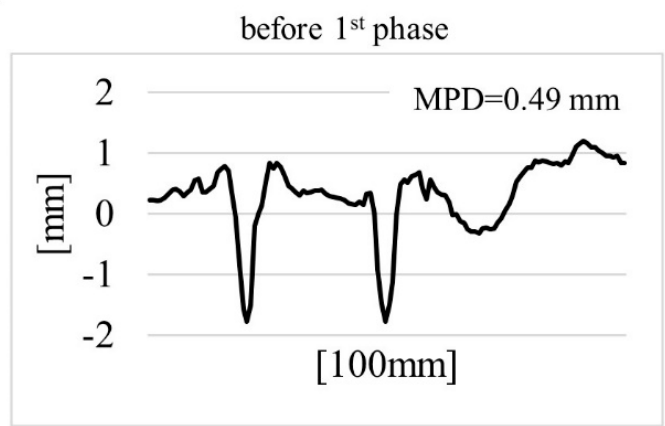

TT

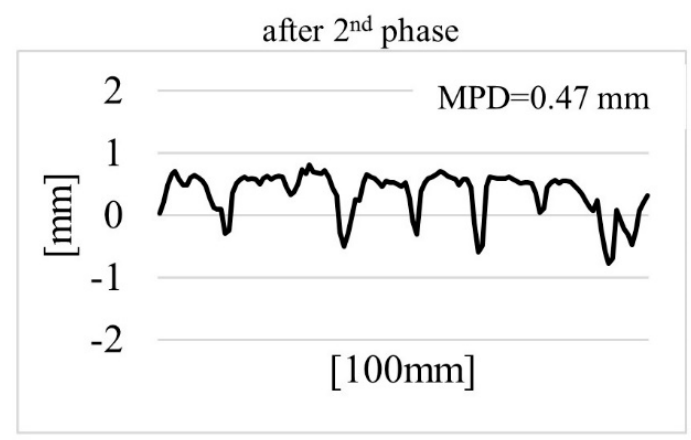

LT

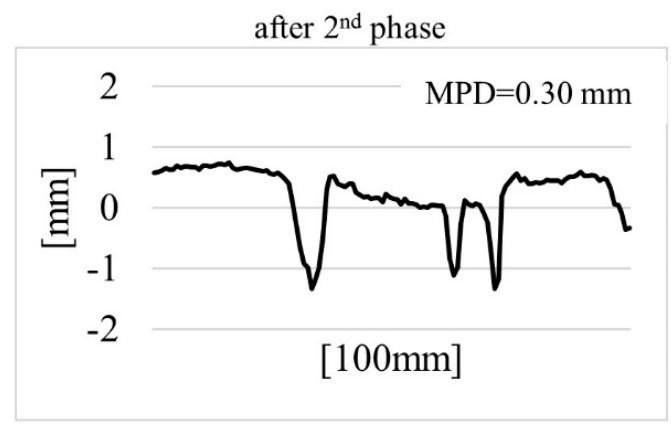

EAC8

e)

before $1^{\text {st }}$ phase

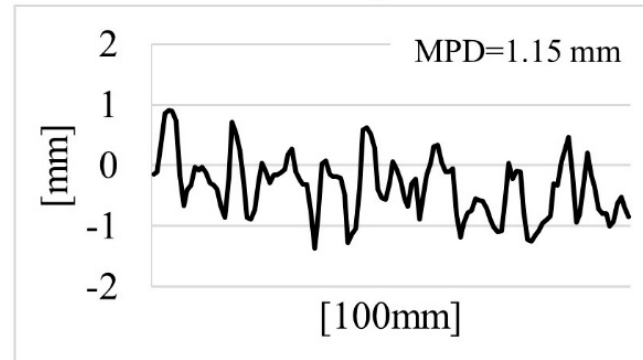

EAC11 f)

before $1^{\text {st }}$ phase

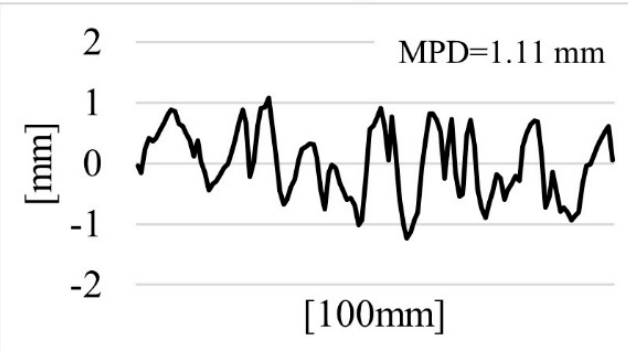

after $2^{\text {nd }}$ phase

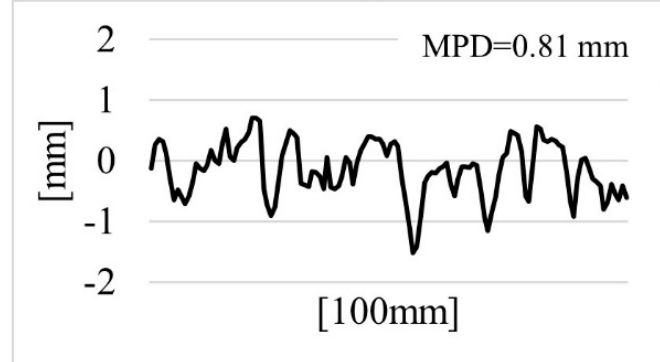

Figure 10. The profiles of the tested surfaces at individual stages of the test: (a) BuD, (b) BrD, (c) TT, (d) LT, (e) EAC8, (f) EAC11. 
The lowest MPD values were recorded on the slabs textured by burlap drag, with an MPD at the level of about $0.25 \mathrm{~mm}$. No changes were noticed in the texture profiles between the initial state and after polishing (Figure 10a).

The greatest differences in MPD values during polishing (decrease by approx. 65\%) were recorded on the surfaces textured by a brush drag (BrD). This was due to the low resistance of pavements textured by this method to factors related to movement. Irregularities created by the brush were removed from the surface (Figure 10b). Significant changes in the texture profiles were recorded on the surfaces grooved transversely and longitudinally-TT and LT (Figure 10c,d).

The highest MPD values were obtained on the EAC slabs. These surfaces had similar profiles both before and after the test (Figure 10e,f). The differences between before the test and after the completion of phase II were caused by the removal of the cement mortar and the polishing of the coarse aggregate. The lowest values of the MPD coefficient of variation, ranging from $11 \%$ to $22 \%$, were obtained for the EAC8 and EAC11 specimens. The other texturing methods had coefficients of variation ranging from $17 \%$ to $36 \%$. This indicates a high variability of MPD with respect to individual textures (Table 4).

The EAC surfaces were the most resistant to the processes taking place during the polishing test. Despite the decrease in the MPD value during the polishing process, the final values were over $0.8 \mathrm{~mm}$ (Table 4). Low MPD values after the polishing process were recorded on the burlap drag, the brush drag, and transverse and longitudinal tined surfaces: $\mathrm{BuD}=0.26 \mathrm{~mm}, \mathrm{BrD}=0.25 \mathrm{~mm}, \mathrm{TT}=0.47 \mathrm{~mm}, \mathrm{LT}=0.30 \mathrm{~mm}$.

\subsection{The Influence of the Texturing Method on the BPN and MPD Coefficients in the Polishing Process}

One-way analysis of variance (Factor A-texturing technique) was used at the particular polishing stages to determine the influence of the texturing methods of concrete pavements on their skid resistances, described by the BPN and MPD parameters. The STATISTICA 13.1 program was used for the calculations.

Tables 5-10 show the results of the variance analyses of the BPN and MPD values obtained at the particular stages of the test. Important parameters are marked in red color.

Table 5. Results of analysis of variance (BPN)—before test.

\begin{tabular}{cccccc}
\hline Effect & $\begin{array}{c}\text { Sum of } \\
\text { Squares, SS }\end{array}$ & $\begin{array}{c}\text { Degrees of } \\
\text { Freedom, df }\end{array}$ & $\begin{array}{c}\text { Mean Sum of } \\
\text { Squares, MS }\end{array}$ & $\boldsymbol{F}_{\boldsymbol{A}, \boldsymbol{o b l}}$ & $\boldsymbol{p}$-Value \\
\hline A & 1601.00 & 5 & 320.20 & 11.79 & 0.00 \\
Error & 489.00 & 18 & 27.20 & - & - \\
Sum & 2090.00 & 23 & - & - & - \\
\hline
\end{tabular}

Table 6. Results of analysis of variance (MPD)—before test.

\begin{tabular}{cccccc}
\hline Effect & $\begin{array}{c}\text { Sum of } \\
\text { Squares, SS }\end{array}$ & $\begin{array}{c}\text { Degrees of } \\
\text { Freedom, df }\end{array}$ & $\begin{array}{c}\text { Mean Sum of } \\
\text { Squares, MS }\end{array}$ & $\boldsymbol{F}_{\boldsymbol{A}, \boldsymbol{o b l}}$ & $\boldsymbol{p}$-Value \\
\hline A & 9.39 & 5 & 1.88 & 75.22 & 0.00 \\
Error & 2.25 & 90 & 27.20 & & \\
Sum & 11.63 & 95 & & & \\
\hline
\end{tabular}

Table 7. Results of analysis of variance (BPN)—after phase I.

\begin{tabular}{cccccc}
\hline Effect & $\begin{array}{c}\text { Sum of } \\
\text { Squares, SS }\end{array}$ & $\begin{array}{c}\text { Degrees of } \\
\text { Freedom, df }\end{array}$ & $\begin{array}{c}\text { Mean Sum of } \\
\text { Squares, MS }\end{array}$ & $\boldsymbol{F}_{\text {A.obl }}$ & $\boldsymbol{p}$-Value \\
\hline A & 326.03 & 5 & 65.37 & 15.69 & 0.00 \\
Error & 75.00 & 18 & 4.17 & & \\
Sum & 401.83 & 23 & & & \\
\hline
\end{tabular}


Table 8. Results of analysis of variance (MPD)—after phase I.

\begin{tabular}{cccccc}
\hline Effect & $\begin{array}{c}\text { Sum of } \\
\text { Squares, SS }\end{array}$ & $\begin{array}{c}\text { Degrees of } \\
\text { Freedom, df }\end{array}$ & $\begin{array}{c}\text { Mean Sum of } \\
\text { Squares, MS }\end{array}$ & $\boldsymbol{F}_{\boldsymbol{A}, \boldsymbol{o b l}}$ & $\boldsymbol{p}$-Value \\
\hline A & 7.76 & 5 & 1.55 & 129.59 & 0.00 \\
Error & 1.08 & 90 & 0.01 & & \\
Sum & 1.28 & 95 & & & \\
\hline
\end{tabular}

Table 9. Results of analysis of variance (BPN)—after phase II.

\begin{tabular}{cccccc}
\hline Effect & $\begin{array}{c}\text { Sum of } \\
\text { Squares, SS }\end{array}$ & $\begin{array}{c}\text { Degrees of } \\
\text { Freedom, df }\end{array}$ & $\begin{array}{c}\text { Mean Sum of } \\
\text { Squares, MS }\end{array}$ & $\boldsymbol{F}_{\boldsymbol{A}, \boldsymbol{o b l}}$ & $\boldsymbol{p}$-Value \\
\hline A & 442.38 & 5 & 88.48 & 50.96 & 0.00 \\
Error & 31.25 & 18 & 1.74 & & \\
Sum & 473.63 & 23 & & & \\
\hline
\end{tabular}

Table 10. Results of analysis of variance (MPD)—after phase II.

\begin{tabular}{cccccc}
\hline Effect & $\begin{array}{c}\text { Sum of } \\
\text { Squares, SS }\end{array}$ & $\begin{array}{c}\text { Degrees of } \\
\text { Freedom, df }\end{array}$ & $\begin{array}{c}\text { Mean Sum of } \\
\text { Squares, MS }\end{array}$ & $\boldsymbol{F}_{\boldsymbol{A}, \boldsymbol{o b l}}$ & $\boldsymbol{p}$-Value \\
\hline A & 5.90 & 5 & 1.18 & 97.64 & 0.00 \\
Error & 1.09 & 90 & 0.01 & & \\
Sum & 6.98 & 95 & & & \\
\hline
\end{tabular}

At the significance level $\alpha=0.05$, a significant influence of factor A (the method of texturing concrete pavements) on the mean BPN values and the MPD parameter was found both before starting the tests on the slab polisher and after each phase of the tests.

The graphic interpretation of the obtained results of the analysis of variance for BPN and MPD values at the particular stages of polishing, in relation to the analyzed methods of texturing concrete pavements, is presented in Figures 11 and 12.

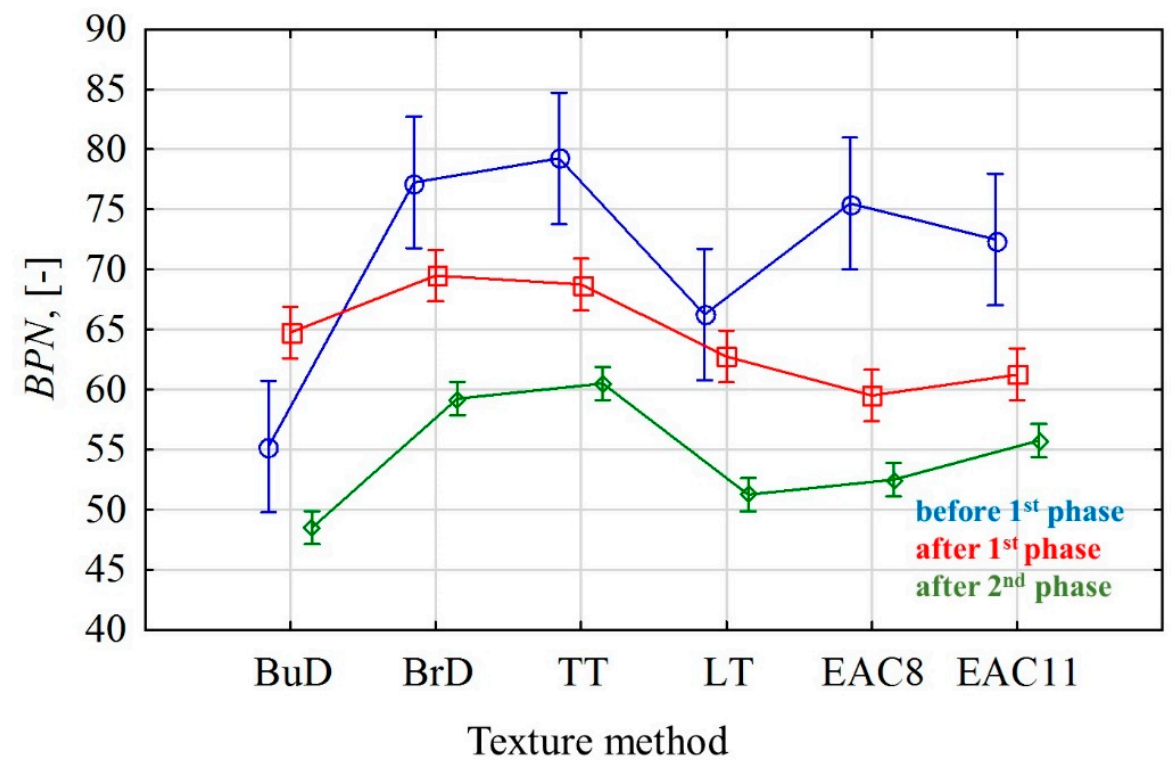

Figure 11. Mean BPN values with the $95 \%$ confidence interval. 


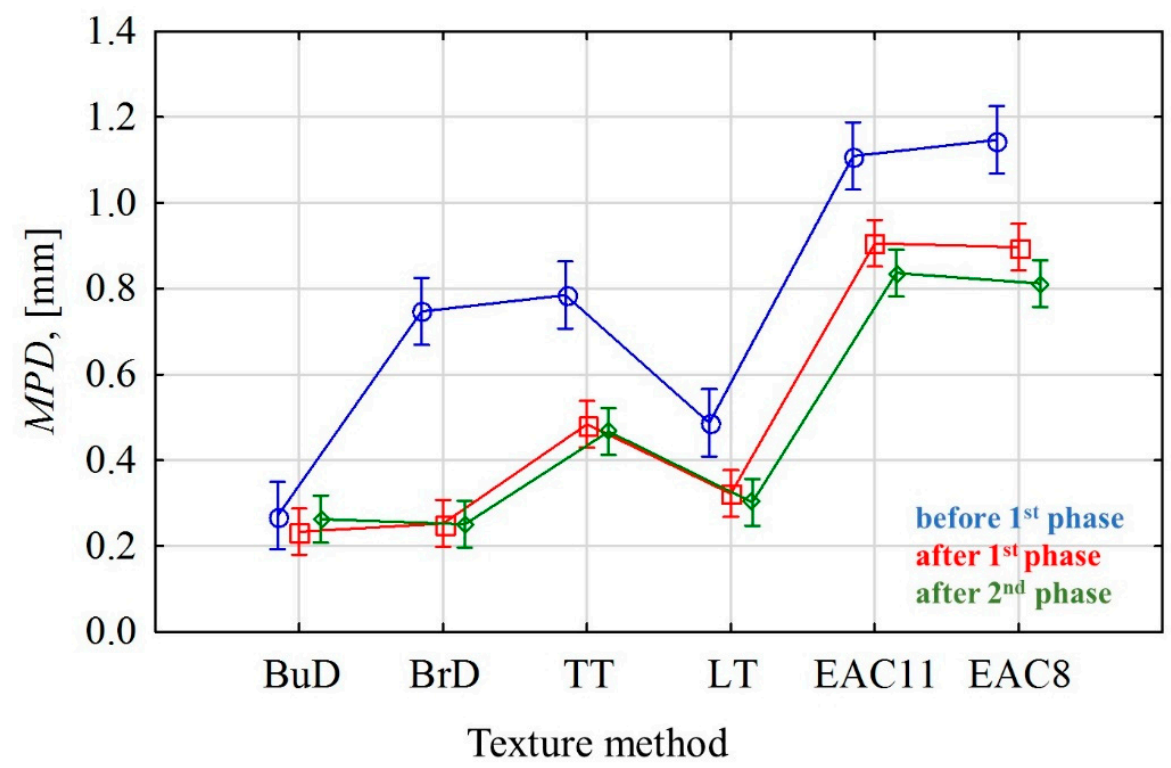

Figure 12. Mean MPD values with the $95 \%$ confidence interval.

There were significant changes affecting the microtextures of the tested surfaces both in phase I and phase II. The intensity of these changes varied at particular stages of the tests, depending on the type of texturing technique. It was found that by far the highest BPN standard deviation values were obtained before the polishing phase in each of the texturing methods (Figure 11). The reason for this phenomenon is the heterogeneity of the microtexture immediately before the test. In the case of the BuD, BrD, LT and TT methods, the fine aggregate grains were exposed on the tested surface, which caused the increasing of the BPN. However, there were places where the texture was smooth (cement mortar), and was characterized by low values of the friction coefficient, hence the high values of standard deviation.

The EAC surfaces immediately after texturing were characterized by the cement mortar remaining after the exposure of the aggregate, which was removed from the aggregates along with the progressing process of polishing.

On the other hand, the macrotextures of these surfaces significantly changed only after the first phase of test, when the conditions simulated the phenomenon of abrasion. The differences between the MPD values of most of the tested surfaces are inconsiderable.

Due to the equal variances between the homogeneous groups in terms of the BPN and MPD levels at the particular stages of the process, an analysis was performed using the Tukey's HSD post-hoc test. The calculations were performed in STATISTICA 13.1.

Tables 11 and 12 present the results of the Tukey's HSD test for the BPN friction coefficient and MPD parameter. The values of the probability level $p<0.05$ are marked in red. They indicate statistically significant differences between the values of the parameters obtained for the individual texturing methods. Figure 13 shows a graphical interpretation of the results of the Tukey's HSD test in relation to the individual test phases in the slab polisher.

The slabs with textured perpendicularly to the driving axis $(\mathrm{BrD}, \mathrm{TT})$ and EAC did not show any significant differences in terms of the initial BPN values (Table 11). No significant differences in BPN values were recorded after phase I and phase II between the slabs with the same polishing direction (BuD and LT, and TT and BrD). In the case of the EAC surface, only the results after the second phase of the test differ significantly. 
Table 11. The results of the Tukey's HSD test calculations for mean BPN values.

\begin{tabular}{|c|c|c|c|c|c|c|}
\hline $\begin{array}{l}\text { Texturing } \\
\text { Method }\end{array}$ & $\mathrm{BuD}$ & BrD & TT & LT & EAC8 & EAC11 \\
\hline \multicolumn{7}{|c|}{ Before test } \\
\hline \multicolumn{7}{|l|}{$\mathrm{BuD}$} \\
\hline $\mathrm{BrD}$ & 0.000 & & & & & \\
\hline $\mathrm{TT}$ & 0.000 & 0.994 & & & & \\
\hline LT & 0.073 & 0.073 & 0.025 & & & \\
\hline EAC8 & 0.001 & 0.997 & 0.906 & 0.173 & & \\
\hline EAC11 & 0.002 & 0.787 & 0.472 & 0.551 & 0.961 & \\
\hline \multicolumn{7}{|c|}{ After phase I } \\
\hline \multicolumn{7}{|l|}{$\mathrm{BuD}$} \\
\hline $\mathrm{BrD}$ & 0.040 & & & & & \\
\hline $\mathrm{TT}$ & 0.109 & 0.995 & & & & \\
\hline LT & 0.735 & 0.002 & 0.007 & & & \\
\hline EAC8 & 0.020 & 0.000 & 0.000 & 0.263 & & \\
\hline EAC11 & 0.200 & 0.000 & 0.001 & 0.898 & 0.825 & \\
\hline \multicolumn{7}{|c|}{ After phase II } \\
\hline \multicolumn{7}{|l|}{$\mathrm{BuD}$} \\
\hline $\mathrm{BrD}$ & 0.000 & & & & & \\
\hline $\mathrm{TT}$ & 0.000 & 0.759 & & & & \\
\hline LT & 0.078 & 0.002 & 0.000 & & & \\
\hline EAC8 & 0.005 & 0.000 & 0.000 & 0.759 & & \\
\hline EAC11 & 0.000 & 0.015 & 0.001 & 0.002 & 0.027 & \\
\hline
\end{tabular}

Table 12. The results of the Tukey's HSD test calculations for mean MPD values.

\begin{tabular}{|c|c|c|c|c|c|c|}
\hline $\begin{array}{c}\text { Texturing } \\
\text { Method }\end{array}$ & BuD & $\mathrm{BrD}$ & TT & LT & EAC8 & EAC11 \\
\hline \multicolumn{7}{|c|}{ Before test } \\
\hline \multicolumn{7}{|l|}{$\mathrm{BuD}$} \\
\hline $\mathrm{BrD}$ & 0.000 & & & & & \\
\hline $\mathrm{TT}$ & 0.000 & 0.984 & & & & \\
\hline LT & 0.003 & 0.000 & 0.000 & & & \\
\hline EAC8 & 0.000 & 0.000 & 0.000 & 0.000 & & \\
\hline EAC11 & 0.000 & 0.000 & 0.000 & 0.000 & 0.985 & \\
\hline \multicolumn{7}{|c|}{ After phase I } \\
\hline \multicolumn{7}{|l|}{$\mathrm{BuD}$} \\
\hline $\mathrm{BrD}$ & 0.996 & & & & & \\
\hline $\mathrm{TT}$ & 0.000 & 0.000 & & & & \\
\hline LT & 0.208 & 0.476 & 0.001 & & & \\
\hline EAC8 & 0.000 & 0.000 & 0.000 & 0.000 & & \\
\hline EAC11 & 0.000 & 0.000 & 0.000 & 0.000 & 0.999 & \\
\hline \multicolumn{7}{|c|}{ After phase II } \\
\hline \multicolumn{7}{|l|}{$\mathrm{BuD}$} \\
\hline $\mathrm{BrD}$ & 0.999 & & & & & \\
\hline $\mathrm{TT}$ & 0.000 & 0.000 & & & & \\
\hline LT & 0.912 & 0.774 & 0.001 & & & \\
\hline EAC8 & 0.000 & 0.000 & 0.000 & 0.000 & & \\
\hline EAC11 & 0.000 & 0.000 & 0.000 & 0.000 & 0.989 & \\
\hline
\end{tabular}




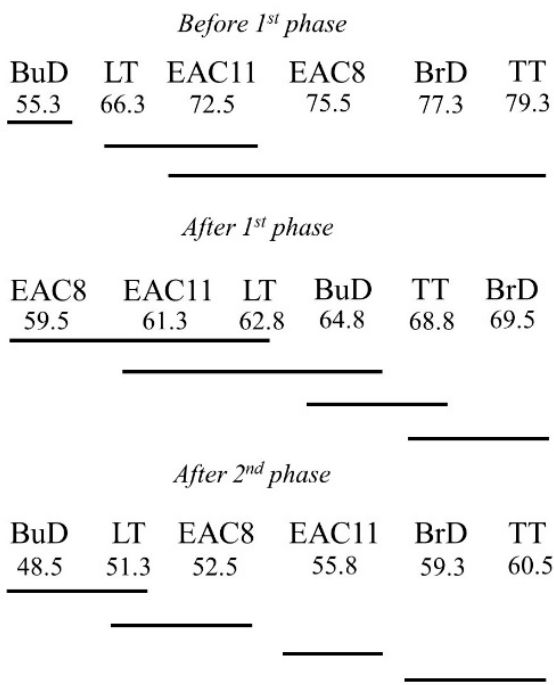

(a)

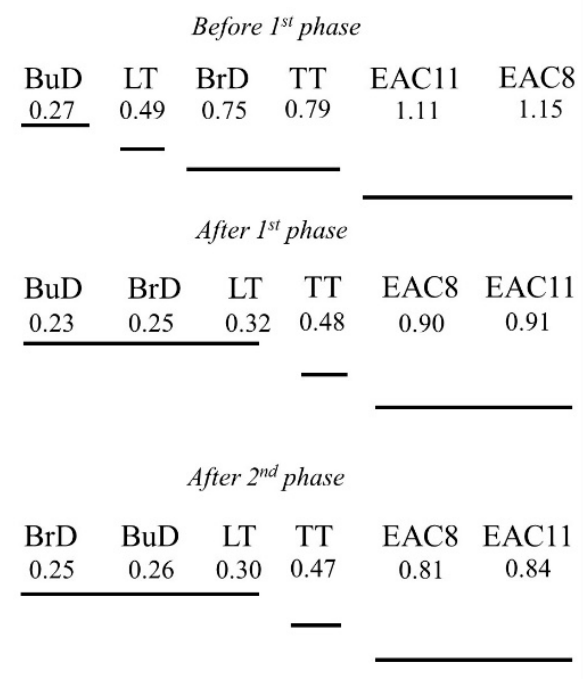

(b)

Figure 13. Homogeneous groups according to the HSD Tukey's test for mean values of (a) BPN, (b) MPD.

Significant differences between MPD values occurred in most of the texturing techniques at each stage of the performed test. The only exceptions are the EAC 8 and EAC 11 pavements. Even though they differed in aggregate size, their roughness profiles were very similar to each other. It was noticed that the $\mathrm{BuD}, \mathrm{LT}$ and $\mathrm{BrD}$ surfaces also showed no significant differences in their mean profile depth values after phases I and II. This is due to the fact that their macrotexture is sensitive when there is a predominance of coarse dirt particles on the surface, which, under the influence of car traffic, rub and destroy the texture made by these methods, while the very small impurities contributing to polishing do not have a destructive effect on the profile depth.

The analysis of changes in the BPN and MPD values of the surfaces textured with various techniques at particular stages of the tests proved that EAC8 and EAC11 are very good technologies for the construction of the wearing course of concrete pavements intended for high-speed roads (above $90 \mathrm{kmph}$ ). They are characterized by the highest MPD values compared to other tested surfaces. Due to the exposed coarse aggregate grains, their resistance to polishing agents will be related to the polishing resistance of the rock $[60,61]$. Therefore, in some countries, this technology has specific requirements for the PSV (Polished Stone Value) of coarse aggregates. The EAC pavements have slightly lower $\mathrm{BPN}$ results compared to $\mathrm{BrD}$ and TT, but higher results than BuD and LT. Because the profile depths were low after the completion of the test, the $\mathrm{BrD}, \mathrm{BuD}$, LT and TT wearing courses are only recommended for lower-speed roads of local importance.

\section{Conclusions}

The application of a laboratory device that simulates the phenomena occurring on the road (abrasion, polishing) allowed us to determine the significant differences between the BPN and MPD parameters for concrete pavements textured with different techniques. Based on the obtained results, the following conclusions were formulated:

1. The least favorable results in relation to BPN and the MPD macrotexture parameter were obtained for the $\mathrm{BuD}$ and LT surfaces. This pavement was characterized by the lowest BPN values (51 and 54, respectively) and a poorly developed macrotexture $(0.26 \mathrm{~mm}$ and $0.30 \mathrm{~mm}$, respectively); 
2. The BrD and TT surfaces were characterized by the highest BPN values in the initial period and after finishing the polishing process. However, they obtained very low macrostructure values $(0.25 \mathrm{~mm}$ and $0.45 \mathrm{~mm})$;

3. The EAC surfaces proved to be the most resistant to conditions simulating the phenomena of abrasion and polishing;

4. Analysis of variance showed significant differences between the BPN and MPD parameters depending on the texturing methods of concrete pavements. The type of texturing has a significant impact on the skid resistance of concrete pavements;

5. The effect of the texturing direction on the skid resistance is shown. In many cases, from the pavements with the same texturing direction, homogeneous groups were created-longitudinal $(\mathrm{BuD}, \mathrm{LT})$, transverse $(\mathrm{BrD}, \mathrm{TT})$ and non-directional $(\mathrm{EAC} 8$, EAC11) (using Tukey's HSD post-hoc test).

In addition, the experiment allowed us to select the texturing method that will be a permanent solution to guarantee good skid resistance on high-speed roads during their period of use. Among the analyzed techniques for texturing concrete pavements, EAC is the most advantageous solution. This is confirmed by the slight changes in the coefficient of friction in the polishing process, and the final BPN values. The MPD values show that the adoption of the EAC method as the primary technique for texturing concrete pavements would be an appropriate solution for high-speed roads with heavy traffic.

It should be emphasized that the evaluation of skid resistance properties at the stage of selecting a technology for road construction provides valuable information about the potential changes taking place on the wearing course of the road pavement. The analysis of the test results allows for the selection of an appropriate solution, taking into account the conditions related to the site location (junction, straight and curve segments) of the road section.

Author Contributions: Conceptualization, M.W., P.G. and W.G.; methodology, P.G., W.G.; validation, P.G. and M.W.; formal analysis, M.W., P.G. and W.G.; investigation, P.G. and M.W.; resources, P.G. and M.W.; data curation, P.G.; writing-original draft preparation, M.W. and P.G.; writing-review and editing, M.W., P.G. and W.G.; visualization, P.G.; supervision, W.G.; project administration, M.W.; funding acquisition, W.G. All authors have read and agreed to the published version of the manuscript.

Funding: This research was funded by Ministry of Science and Higher Education, grant number No. WZ/WB-IIL/1/2020 at Bialystok University of Technology.

Institutional Review Board Statement: Not applicable.

Informed Consent Statement: Informed consent was obtained from all subjects involved in the study.

Data Availability Statement: The data presented in this study are available in the database of the authors at the Faculty of Civil Engineering and Environmental Science.

Conflicts of Interest: The authors declare no conflict of interest. The funders had no role in the design of the study; in the collection, analyses, or interpretation of data; in the writing of the manuscript, or in the decision to publish the results.

\section{References}

1. Ahammed, M.A.; Tighe, S.L. Concrete pavement surface textures and multivariables frictional performance analysis: A North American case study. Can. J. Civ. Eng. 2008, 35, 727-738. [CrossRef]

2. Rasmussen, R.O.; Resendez, Y.A.; Chang, G.K.; Ferragut, T.R. Concrete Pavement Solutions for Reducing Tire-Pavement Noise; National Concrete Pavement Technology Center, Iowa State University: Ames, IA, USA, 2004.

3. Snyder, M.B. Concrete Pavement Texturing. In Fhwa-Hif-17-011; Tech Brief: Vishnu Garden, Delhi, 2019.

4. Izevbekhai, B.I.; Watson, M. Evaluation of concrete pavement texturing practice in Minnesota using the weather accident evaluation criterion. In Report No. MN/RC-2008-46; Minnesota Department of Transportation: St. Paul, MN, USA, 2008.

5. Rasmussen, R.O.; Wiegand, P.D.; Fick, G.J.; Harrington, D.S. How to Reduce Tire-Pavement Noise: Better Practices for Constructing and Texturing Concrete Pavement Surfaces. In Report No. DTFH61-06-H-00011 Work Plan 7 TPF-5(139); Federal Highway Administration, U.S. Department of Transportation: Ames, IA, USA, 2012.

6. Donovan, P.R.; Rymer, B. Effects of Aging on Tire-Pavement Noise Generation for Concrete Pavements of Different Textures. Transp. Res. Rec. 2011, 2233, 152-160. [CrossRef] 
7. Skarabis, J.; Stockert, U. Noise emission of concrete pavement surfaces produced by diamond grinding. J. Traffic Transp. Eng. 2015, 2, 81-92. [CrossRef]

8. Altreuther, B.; Beckenbauer, T.; Skarabis, J.; Gehlen, C.; Villaret, S.; Frohbose, B. Acoustical assessment of exposed aggregate concrete roads. In Proceedings of the 12th International Symposium on Concrete Roads 2014, Prague, Czech Republic, 23-26 September 2014.

9. Šernas, O.; Zofka, A.; Vaitkus, A.; Gražulytè, J. The effect of exposed aggregate concrete gradation on the texture characteristics and durability. Constr. Build. Mater. 2020, 261. [CrossRef]

10. Wasilewska, M.; Gardziejczyk, W.; Gierasimiuk, P. Evaluation of skid resistance of exposed aggregate concrete pavement in the initial exploatation period = Ocena właściwości przecipoślizgowych nawierzchni betonowych $\mathrm{z}$ odkrytym kruszywem $\mathrm{w}$ poczatkowym okresie ich użytkowania. Roads Bridges 2017, 16, 301-314. [CrossRef]

11. Akkari, A.; Izevbekhai, B. Composite Pavements and Exposed Aggregate Texturing at MnROAD: Cells 70, 71, and 72 Construction Report and Early Performance Evaluation. In Final Report MN/RC 2012-29; Office of Materials and Road Research Minnesota Department of Transportation: Maplewood, MN, USA, 2012.

12. Teuns, K.C.J.G.; Stet, M.J.A.; van Keulen, W. Full Scale Pavement Tests of Exposed Concrete Aggregates: Acoustical Aspects and Friction Characteristics. In Proceedings of the 9th International Symposium on Concrete Roads, Istanbul, Turkey, 27-30 May 2003.

13. Daskova, J.; Kudrna, J. The experience with Wehner/Schulze procedure in the Czech Republic, In Proceedings of SIIV-5th International Congress-Sustainability of Road Infrastructures. Procedia-Soc. Behav. Sci. 2012, 53, 1035-1044. [CrossRef]

14. Tompkins, D.; Khazanovich, L.; Darter, M.I. 2008 Survey of European Composite Pavements; Transportation Research Board: Washington, DC, USA, 2010.

15. Sommer, H. Longtime experience with exposed aggregate surfaces in Austria. Theme 3-Pavement Performance and Evaluation. In Proceedings of the 8th International Symposium on Concrete Roads, Lisbon, Portugal, 13-16 September 1998 ; pp. $117-121$.

16. Anderson, K.W.; Uhlmeyer, J.S.; Russell, M.; Weston, J. Evaluation of Long-Term Pavement Performance and Noise Characteristics of the Next Generation Concrete Surface. In Report No. Wa-Rd 767.1; Washington State Department of Transportation: Washington, WA, USA, 2011.

17. Cable, J.K.; Wiegand, P. Surface characteristics next generation grooving and grinding Iowa test site construction. In Final Report; National Concrete Pavement Technology Center: Aimes, IA, USA, 2010.

18. Guada, I.M.; Rezaei, A.; Harvey, J.T.; Spinne, D. Evaluation of Grind and Groove (Next Generation Concrete Surface) Pilot Projects in California. In Report No.: UCPRC-RR-2013-01; California Department of Transportation, Division of Research, Innovation and Spatial Information: Berkeley, CA, USA, 2013.

19. Scofield, L. Development and Implementation of the Next Generation Concrete Surface. In Final Report; IGGA/ACPA: Coxsackie, NY, USA, 2016.

20. Scofield, L. Development of the Next-Generation, Low-Maintenance Concrete Surface. In Proceedings of the National Conference on Preservation, Repair, and Rehabilitation of Concrete Pavements, St. Louis, MO, USA, 21-24 April 2009; pp. 269-286.

21. Sandberg, U.; Goubert, L.; Vieira, T. New Measures for Characterization of Negative Surface Textures. In Proceedings of the 8th Symposium on Pavement Surface Characteristics: SURF 2018-Vehicle to Road ConnectivityBrisbane, Queensland, Australia, 2-4 May 2018.

22. Fwa, T.F. Skid resistance determination for pavement management and wet-weather road safety. Int. J. Transp. Sci. Technol. 2017, 6, 217-227. [CrossRef]

23. Larson, R.; Scofield, L.; Sorenson, J. Providing Durable, Safe, and Quiet Highways. In Proceedings of the 8th International Conference on Concrete Pavements, International Society for Concrete Pavements, Bridgeville, PA, USA, 14-18 August 2005.

24. Cairney, P.; Styles, E. A Pilot Study of the Relationship Between Macrotexture and Crash Occurrence. In Road Safety Research Report Cr223; ARRB Transport Research Ltd. to Australian Transport Safety Bureau: Victoria, Australia, 2005.

25. Piyatrapoomi, N.; Weligamage, J.; Kumar, A.; Bunker, J. Identifying relationship between skid resistance and road crashes using probability-based approach. In Proceedings of the 2nd International Safer Roads Conference, Cheltenham, UK, 11-14 May 2008.

26. Pulugurtha, S.S. Relationship between Pavement Macrotexture and Crash Incidences on North Carolina Roads. In Final Report FHWA/NC/2007-12; North Carolina Department of Transportation: Charlotte, NC, USA, 2008.

27. Wallbank, C.; Viner, H.; Smith, L.; Smith, R. The relationship between collisions and skid resistance on the Strategic Road Network. In Public Project Report Ppr806; TRL Limited: Crowthorne, UK, 2016.

28. Chu, L.J.; Fwa, T.F. Pavement skid resistance consideration in rain-related wet-weather speed limits determination. Road Mater. Pavement Des. 2018, 83, 351-368. [CrossRef]

29. Wambold, J.C.; Henry, J.J.; Hegmon, R.R. Evaluation of pavement surface texture significance and measurement techniques. Wear 1982, 83, 351-368. [CrossRef]

30. Do, M.-T.; Cerezo, V.; Yannick, B.; Kane, M. Influence of Thin Water Film on Skid Resistance. J. Traffic Transp. Eng. 2020, 2, 36-44. [CrossRef]

31. Liu, J.; Guan, B.; Chen, H.; Liu, K.; Xiong, R.; Xie, C. Dynamic Model of Polished Stone Value Attenuation in Coarse Aggregate. Materials 2020, 13, 1875. [CrossRef] [PubMed]

32. Chu, L.; Guo, W.; Fwa, T.F. Theoretical and practical engineering significance of British pendulum test. Int. J. Pavement Eng. 2020. [CrossRef] 
33. Chen, Y.; Wang, K.J.; Zhou, W.F. Evaluation of surface textures and skid resistance of pervious concrete pavement. J. Cent. South Univ. 2015, 20, 520-527. [CrossRef]

34. Chandler, J.W.B.E.; Phillips, S.M.; Roe, P.G.; Viner, H.E. Quieter concrete roads: Construction, texture, skid resistance and noise. TRL Rep. Trl576 2003, 12, 40.

35. Chen, Y.; Zhang, Q. Test Study on Abrasion of Skid resistant Textures on Concrete Pavements. In Proceedings of the GeoHunan International Conference 2009, Hunan, China, 3-6 August 2009.

36. Hofko, B.; Kugler, H.; Chankov, G.; Spielhofer, R. A laboratory procedure for predicting skid and polishing resistance of road surfaces. Int. J. Pavement Eng. 2019, 20, 439-447. [CrossRef]

37. Kudrna, J.; Daskova, J.; Nekulova, P.; Nekula, L. Skid resistance of concrete pavements and their durability. In Proceedings of the 12th International Symposium on Concrete Roads 2014, Prague, Czech Republic, 23-26 September 2014.

38. Li, B.; Kang, H.-W.; Zhang, Z.-W. Comparison of skid resistance and noise between transverse and longitudinal grooving pavements in newly constructed concrete pavement. Adv. Mater. Res. 2012, 446-449, 2637-2640. [CrossRef]

39. Nelson, T. Evaluation of skid resistance of turf drag textured concrete pavements. In Report No. MN/RC-2011-12; Minnesota Department of Transportation: St. Paul, MN, USA, 2011.

40. Cerezo, V.; Rado, Z.; Kane, M. Comparison of European and American Methods for Harmonizing Friction MeasurementsResults of 1st European Pavement Friction Workshop. In Proceedings of the 8th Symposium on Pavement Surface Characteristics: SURF 2018, Brisbane, Queensland, 2-4 May 2018.

41. Nekula, L.; Stryk, J.; Nekulova, P.; Brezina, I. Potential Improvement in Data Interpretation Regarding Simultaneous Measurement of Friction Coefficient and IRI. In Proceedings of the 8th Symposium on Pavement Surface Characteristics: SURF 2018, Brisbane, Queensland, 2-4 May 2018.

42. Weller, D.E.; Maynard, D.P. The influence of materials and mix design on the skid resistance value and texture depth of concrete. In Report LR 334; Road Research Laboratory Ministry of Transport RRT: Wokingham, Great Britain, 1970.

43. Hall, J.W.; Smith, K.L.; Titus-Glover, L.; Wambold, J.C.; Yager, T.J.; Rado, Z. Guide for pavement friction NCHRP Web-Only Document 108. In Final Report for NCHRP Project 01-43; National Cooperative Highway Research Program: Washington, DC, USA, 2009.

44. Henry, J.J. Evaluation of Pavement Friction Characteristics. In Nchrp Synth. 291; Transportation Research Board: Washington, DC, USA, 2000.

45. Wesolowski, M.; Blacha, K. Evaluation of airfield pavement micro and macrotexture in the light of skid resistance (friction coefficient) measurements. In Proceedings of the 64 Scientific Conference of the Committee for Civil Engineering of the Polish Academy of Sciences and the Science Committee of the Polish Association of Civil Engineers (PZITB), Krynica Zdroj, Poland, 16-20 September 2019. [CrossRef]

46. Wasilewska, M.; Gardziejczyk, W.; Gierasimiuk, P. Comparison of measurement methods used for evaluation the skid resistance of road pavements in Poland-case study. Int. J. Pavement Eng. 2018, 21, 1662-1668. [CrossRef]

47. PN-EN 12350-3:2019-07. Testing Fresh Concrete; Polish Standard; Vebe Test: Warsaw, Poland, 2019.

48. PN-EN 12350-7:2011. Testing Fresh Concrete_Part 7: Air Content; Polish Standard; Pressure Methods: Warsaw, Poland, 2011.

49. PN-EN 12350-6:2019. Testing Fresh Concrete; Polish Standard; Density: Warsaw, Poland, 2019.

50. PN-EN 12390-7:2019. Testing Fresh Concrete; Polish Standard; Air Content. Pressure Methods: Warsaw, Poland, 2019.

51. PN-EN 12390-3:2019. Testing Hardened Concrete; Polish Standard; Compressive Strength of Test Specimens: Warsaw, Poland, 2019.

52. PN-EN 12390-5:2019. Testing Hardened Concrete; Polish Standard; Flexural Strength of Test Specimens: Warsaw, Poland, 2019.

53. PN-EN 13877-2:2013. Concrete Pavements; Polish Standard; Functional Requirements for Concrete Pavements: Warsaw, Poland, 2013.

54. Wasilewska, M.; Gardziejczyk, W. Assessment of Skid Resistance of Asphalt Mixtures in Laboratory Conditions. Arch. Civ. Eng. 2012, 58, 521-534. [CrossRef]

55. ASTM E303-93. Standard Test Method for Measuring Surface Frictional Properties Using the British Pendulum Tester; American Society for Testing and Materials: West Conshohocken, PA, USA, 2018.

56. ASTM E2157-15. Standard Test Method for Measuring Pavement Macrotexture Properties Using the Circular Track Meter; American Society for Testing and Materials: West Conshohocken, PA, USA, 2019.

57. van Bijsterveld, W.; del Val, M.A. Towards quantification of seasonal variations in skid resistance measurements. Road Mater. Pavement Des. 2016, 17, 477-486. [CrossRef]

58. Wasilewska, M.; Gardziejczyk, W. Evaluation of microtexture changes of coarse aggregate during simulated polishing. Arch. Civ. Eng. 2016, 62, 19-34. [CrossRef]

59. Yun, D.; Hu, L.; Tang, C. Tire-Road Contact Area on Asphalt Concrete Pavement and Its Relationship with the Skid Resistance. Materials 2020, 13, 615. [CrossRef] [PubMed]

60. Kogbara, R.B.; Masad, E.A.; Kassem, E.; Scarpas, A.T.; Anupam, K. A state-of-the-art review of parameters influencing measurement and modeling of skid resistance of asphalt pavements. Constr. Build. Mater. 2016, 114, 602-617. [CrossRef]

61. Kane, M.; Edmondson, V. Long-term skid resistance of asphalt surfacings and aggregates' mineralogical composition: Generalisation to pavements made of different aggregate types. Wear 2020, 454-455. [CrossRef] 